\title{
Systematic Map of the Social Impact Assessment Field
}

\author{
Ricardo J. Bonilla-Alicea and Katherine Fu * \\ Woodruff School of Mechanical Engineering, Georgia Institute of Technology, Atlanta, GA 30332, USA \\ * Correspondence: katherine.fu@me.gatech.edu; Tel.: +1-404-385-3810
}

Received: 18 July 2019; Accepted: 26 July 2019; Published: 30 July 2019

\begin{abstract}
Social impact assessment (SIA) provides a methodology for defining, monitoring and employing measures to demonstrate the benefits and/or harms created for target communities through evidence of social outcomes and impacts. Although a recent increase in the number of applications is seen, SIA lacks consensus in its methodology, which increases ambiguity and complicates the generalization of any results obtained from individual studies. The objectives of this study are to investigate the methodology of SIA in order to define trends, state of the art, limitations, knowledge gaps, and to recommend future research directions. This study employs a systematic mapping to determine the methods available to perform SIA, and more importantly to identify a set of fundamental challenges faced by practitioners using SIA. Articles are searched through online databases, and are limited to the English language. A total of 81 articles published between 2009 and 2019 were selected, of which 49 included a case study application. A total of 12 fundamental challenges were identified, based upon the screened articles, which serve as a starting point for future research directions to further enhance the SIA methodology.
\end{abstract}

Keywords: impact assessment; social impact assessment; life cycle assessment; social life cycle assessment; social impacts; social sustainability; systematic mapping; case studies

\section{Introduction}

A common definition of sustainability emerged from the Report of the World Commission on Environment and Development: Our Common Future: "Sustainable development seeks to meet the needs and aspirations of the present without compromising the ability to meet those in the future." [1]. Sustainability is often represented by the tripartite model, in which the concept is divided into three interconnected pillars: The economic, environmental and social pillars [2]. By defining sustainability as three separate and even autonomous components, the analysis of sustainability becomes easier from a technical point of view, as each pillar can be evaluated separately. This model has been strongly criticized, because it balances and makes trade-offs among the three pillars, which should be a last resort [3]. As a result, many studies perform analyses separately, and then integrate the results into the final steps to perform a global assessment. The increased interest in sustainability has resulted in the field of sustainable product development. Sustainable product development involves the adoption of lifecycle technologies that reduce the negative economic, environmental and social impacts of a product. Among the different methods available for performing social assessments, social impact assessment (SIA) provides a method to assess the social impacts of a single process and/or plant related to a product or service, and it is often used in the context of development projects [4]. A social impact assessment is defined as "a systematic appraisal of impacts on the quality of life of persons and communities whose environment is affected by a proposed policy, plan, program or project" [5].

Relative to the environmental and economic assessment fields, the social impact assessment field is not well studied. This can be explained by the perception that ecological aspects are more urgent than social aspects, and that there are complex relationships and interdependencies between social 
and economic issues [6]. Social impact assessments were developed in the 1970s [7] as an extension of environmental impact assessments [8], which resulted in the application of environmental impact approaches to perform the social assessments. Unfortunately, this results in significant technical challenges, as social impacts tend to be more far reaching than environmental impacts, which are usually more focused in the locations being studied.

Two publications that have contributed to the advancement of the SIA field are the 2009 United Nations Environment Program/Society of Environmental Toxicology and Chemistry (UNEP/SETAC) Guidelines and the 2013 UNEP/SETAC Methodological Sheets. An explanation of the methodologies presented in both publications is offered in the results section of this article. Although the two aforementioned publications have resulted in an increased number of publications related to SIA in recent years [9-12], SIA practitioners still face significant challenges relative to environmental and economic assessments. In contrast to performing environmental and economic assessments, social impacts are highly subjective, because there are no clear pathways established between the inputs and outputs. Furthermore, the field has not reached standardization, and there is significant variability in the approaches followed when performing social impact assessments. This lack of standardization results in the impossibility of achieving consensus among the results obtained from different studies, making the process of consolidating knowledge more difficult.

A recent increase in the number of SIA studies has resulted in a large body of work that appears to lack standardization. An approach to address this issue is to analyze the large collection of results and studies in SIA with the purpose of integrating individual findings, to establish a detailed understanding of the field by means of a systematic evidence synthesis method. Evidence synthesis methods follow a rigorous and transparent process, aiming to reduce reviewer selection and publication bias, and to enable the reader to review all of the decisions made in order to screen the selected articles [13]. A well-regarded evidence synthesis method is the systematic review. A systematic review is defined as "a structured evaluation of the literature with the goal of answering a specific research or application question with a synthesis of the best available evidence." [14]. This method reduces the subjectivity in drawing conclusions [10,15], reveals trends, relationships and gaps in the literature in order to synthesize, organize and evaluate what is known and what is unknown within a particular field [16].

Although a systematic review is a powerful method for performing evidence synthesis, its feasibility to answer open frame questions such as the one presented in this study, is questionable. Open framed questions require the inclusion of evidence from heterogeneous sources, which may difficult the result synthesis process presented in the systematic reviews [13]. Answering this research question involves the collection of information sources that may not allow a quantitative synthesis to answer the research question. Based upon the nature of the study, the authors opted for performing a systematic mapping of the social impact assessment field. By means of a systematic mapping, the objective of this study is to determine the state of the knowledge of the social impact assessment field, identify research gaps for future research directions, and to identify a set of fundamental challenges involving the application of social impact assessments. The research question investigated through the systematic mapping is the following: "What are the current methods available to perform social impact assessments, and how have they been implemented?" Details about the systematic mapping procedure are presented in the Materials and Methods section (Section 2) to ensure process transparency, results replicability and an appropriate update of results if any related data is generated in future studies [14].

\section{Product Life Cycle, Life Cycle Impact Assessment and Nomenclature}

The product life cycle refers to the processes involved in the creation of a product and their interactions with the surrounding environment, from the extraction of the raw materials to the return of the product as "waste" to Earth, a process also known as "cradle to grave" [17].

By adopting a life cycle approach, the environmental, economic or social impacts of the product are evaluated at all steps of its life. The product life cycle is commonly divided into the following 
four steps: Raw material extraction and production, product manufacturing, product use and any maintenance associated with it, and product disposal or end of life treatment [17].

Although not all impact assessments are based on the life cycle of the product, the literature shows that it is the preferred methodology by practitioners. The procedure and terms explained in this section are based on the International Organization for Standardization (ISO) 14044, which lays out the steps for performing a life cycle impact assessment [18], and the 2009 UNEP/SETAC guidelines for the social impact assessment of products based on performance reference points [8]. Table 1 provides a summary of terms related to environmental and social life-cycle assessments as a reference for the interested reader that is not familiarized with LCA terminology.

Table 1. Nomenclature of terms used in article.

\begin{tabular}{ll}
\hline Term & \multicolumn{1}{c}{ Definition } \\
\hline & Summing or bringing together of information (e.g., data, indicator \\
& results, etc.) from smaller units into a larger unit. (e.g., from \\
& inventory indicator to subcategory). In Social Lifecycle Assessment \\
Aggregation & (S-LCA), the aggregation of data may be done at the life cycle \\
& inventory or impact assessment phase, and should not be done in a \\
& way that leads to any loss of information about the location of the \\
unit processes [8].
\end{tabular}

Partitioning of the input or output flows of a process or a product

system between the product system under study and one or more

Allocation other product systems inside of the system boundaries [18]. It is basically the division of impacts between the product system under study, and one or more product systems with which it interacts [19].

Area of Protection (AOP) Cluster of category endpoints of recognizable value to society e.g., human health, natural resources, natural environment and man-made environment.

\begin{tabular}{|c|c|}
\hline Characterization & $\begin{array}{l}\text { Determination and/or calculation of results for subcategory } \\
\text { indicators [8]. }\end{array}$ \\
\hline Classification & $\begin{array}{l}\text { Relating of the inventory data to particular stakeholder categories, } \\
\text { impact categories and subcategories [8]. }\end{array}$ \\
\hline Environmental Endpoint & $\begin{array}{l}\text { Represents the environmental damages caused to an area of } \\
\text { protection (AOP), i.e., the biotic natural environment or human } \\
\text { health [8]. }\end{array}$ \\
\hline Functional Unit & $\begin{array}{l}\text { Quantified performance of a product system for use as a reference } \\
\text { unit [18]. }\end{array}$ \\
\hline Impact Indicator & Quantifiable representation of an impact category [18]. \\
\hline Impact Category & $\begin{array}{l}\text { Logical groupings of S-LCA results, related to social issues of } \\
\text { interest to stakeholders and decision makers [8]. }\end{array}$ \\
\hline Normalization & $\begin{array}{l}\text { Calculation of the magnitude of category indicator results relative to } \\
\text { reference information [18]. }\end{array}$ \\
\hline Input & Product, material or energy flow that enters a unit process [18]. \\
\hline Life Cycle Inventory (LCI) & $\begin{array}{l}\text { Phase of a S-LCA in which data are collected, the systems are } \\
\text { modeled, and the life cycle inventory (LCI) results are obtained [8]. }\end{array}$ \\
\hline Midpoint & $\begin{array}{l}\text { Covers an environmental problem that stands between the LCI and } \\
\text { the final damage in the AOP [8]. }\end{array}$ \\
\hline Output & Product, material or energy flow that leaves a unit process [18]. \\
\hline
\end{tabular}


Table 1. Cont.

\begin{tabular}{cl}
\hline \multicolumn{1}{c}{ Term } & \multicolumn{1}{c}{ Definition } \\
\hline Performance Reference Point (PRP) & $\begin{array}{l}\text { Additional information used in characterization models, which may } \\
\text { be internationally set thresholds, goals or objectives according to } \\
\text { conventions and best practices, etc. [8]. }\end{array}$ \\
\hline Social Endpoint & $\begin{array}{l}\text { A social attribute or aspect identifying an issue giving cause for } \\
\text { concern (e.g., well-being of stakeholders). Adapted from } \\
\text { ISO 14040 [8,18] }\end{array}$ \\
\hline Stakeholder & $\begin{array}{l}\text { Individual or group that has an interest in or is impacted by any } \\
\text { activities or decisions of an organization [20]. }\end{array}$ \\
\hline Stakeholder Category & $\begin{array}{l}\text { Cluster of stakeholders that are expected to have similar interests } \\
\text { due to their similar relationship to the investigated product } \\
\text { systems [8]. }\end{array}$ \\
\hline Stakeholder Theory & $\begin{array}{l}\text { Theory that identifies and models the stakeholder groups of a } \\
\text { corporation, and both describes and recommends methods by which } \\
\text { management can give due regard to the interests of those } \\
\text { groups [21]. }\end{array}$ \\
\hline System Boundaries & $\begin{array}{l}\text { Set of criteria specifying which unit processes are part of a product } \\
\text { system [18]. }\end{array}$ \\
\hline Converting and possibly aggregating indicator results across impact \\
categories, using numerical factors based on value-choices; data \\
prior to weighting should remain available [18].
\end{tabular}

There are four phases in a life-cycle assessment (LCA) analysis as per the ISO 14044 [18]:

1. The goal and scope definition phase: Goal definition involves explaining the intended application, the reasons for performing the study, and the intended audience. The scope defines the product system to be studied, the functional unit, system boundaries, allocation procedures, any assumptions made in the analysis and interpretations to be used for the results [18].

2. The inventory analysis phase: The life cycle inventory phase involves the collection and quantification of the inputs and outputs to be considered for the analysis [18]. The data collected is used for prioritization, site specific evaluation, and for the impact assessment procedure [8].

3. The impact assessment phase: This step involves the classification, aggregation and characterization of data according to performance reference points. At this phase, the impact categories and subcategories are selected, along with the characterization methods and models. The collected data is also related to subcategories and impact categories, and the results for the subcategory indicators are calculated [8].

4. The result interpretation phase: This phase involves the process of assessing the results from the study in order to draw conclusions. This phase has the following objectives: To analyze the results, reach conclusions, explain the limitations of the study, provide recommendations and to make an adequate report of the results [8].

\section{Materials and Methods}

\subsection{Systematic Mapping Methodology}

Because there is no current standard to perform systematic mapping in the social impact assessment field, the methodology presented in this study is based on the work of James et al. [13], which has been adapted to the field of social impact assessment. Due to the existing similarities between systematic mapping and systematic reviews, this study incorporates elements from the work of Biolchini, et al. [22], Mulrow [23], Petti, et al. [10], Zamagni, et al. [15] and Zumsteg, et al. [14]. The methodology consists of a series of sequential steps that are explained in more detail in the following subsections. This 
evidence synthesis method was selected over the systematic review for numerous reasons. First, the objective of the research question is to describe the state of knowledge of the social impact assessment field. Answering this research question requires researching broad topics that are not suited for systematic reviews, which are usually used for more focused topics. Second, the articles included in the search database are from numerous sources, including published articles, company reports and grey literature. The systematic mapping is better accommodating for the heterogeneous information sources considered in the study relative to the systematic review. Third, the synthesis of the selected articles follows a meta-data approach that aims at identifying trends in the literature, research gaps and clusters, but no quantitative or qualitative synthesis of the results is to be presented, as is commonly done in a systematic review.

\subsubsection{Review Team}

The review team for performing the systematic map consists of two members. The objective, scope, research question as well as the inclusion criteria, were developed by both team members. One of the team members performed the literature search and article screening. This same person performed the coding of the results to be used for creating the visualization of the results. The other team member served as a manager to ensure quality assurance along the complete process. The review team also discussed and agreed upon selecting the systematic map over the systematic review method based on the objectives and characteristics of the study.

\subsubsection{Systematic Map Research Question and Objective}

The objective of the systematic map in this study is to describe the current state of knowledge of the social impact assessment field with respect to the methods available to perform such studies. The research question to be answered is the following: "What are the current methods available to perform social impact assessments, and how have they been implemented?" In order to better answer and organize the results, the main research question has been divided into the following sub-questions:

- How many case studies were published between 2009 and 2019?

- What are the areas of application of social impact assessments?

- How are these applications being carried out?

- What are the subjects being assessed for social impacts?

- Which are the geographical areas being considered in social impact assessment studies?

- What are the main challenges for each of these social impact assessment methods?

\subsubsection{Keywords and Source Databases}

A literature search was selected as the method to search for information. The systematic map focused mostly on academic literature from peer-reviewed journals, academic conference proceedings, and to a lesser extent, grey literature. Book chapters and books were excluded from the database because the information is presented less concisely relative to scholarly articles. Because the authors aimed to determine the state of knowledge of the social impact assessment field from a high-level perspective, book chapters and books in general were considered too focused and too detailed for the scope of this study. The results from this study should motivate more focused studies, such as systematic reviews, and those should include book chapters and books in their analysis, as those aim to have a more detailed understanding of the topics under study. The main search database was SCOPUS, supplemented by Google Scholar and the Google search engine. The search string used in the systematic map consisted of the following two areas (shown in bold below), with their respective synonyms:

\section{Social Impact Assessment}


a. Social Life Cycle Assessment OR Social Life Cycle Sustainability OR Social Impact Method OR Social Innovation OR Social Assessment or Social Sustainability

\section{Product Development}
b.
Product Innovation OR Product Engineering Design

\subsubsection{Inclusion and Exclusion Criteria}

An important aim of this study was to gather evidence related to social impact assessment regardless of the discipline. Instead of performing a focused literature search and restricting the articles only to those in the Engineering or Mathematics fields for example, the authors wanted to gather as much evidence as possible, regardless of the field of origin. In addition, no restriction was placed with regards to the country of origin of the study or the industry of application.

The authors knew a priori about the breadth of applications being covered by social impact assessments, and the goal was to obtain knowledge from heterogeneous sources to gather a wide range of evidence and topics. The only two major inclusion restrictions were that the articles were written in the English language, and that they either provide a social impact assessment method or provide a review of other social impact assessment studies.

\subsubsection{Screening for Evidence}

As with systematic reviews, the systematic map follows a structured and objective methodology for screening the literature information. The following procedure was carried out to determine if the article would be selected as part of the systematic map:

1. Read the article title and keywords

2. Read the abstract

3. Read the introduction and conclusion

4. Read the full text

Each step was performed in a sequential manner, continuing to the next step if the previous step did not allow the author to determine whether the articles should be selected or not. By following this procedure, a total of 81 journal articles were selected, of which 49 included a case study application. An additional number of grey literature documents were selected based on references found in the journal articles themselves.

\subsubsection{Coding}

Coding is the process of assigning categories to generic and detailed information of the selected articles. It organizes, categorizes and describes the records included in the systematic map, allowing users to organize the results by a particular topic or a descriptor of the articles [13,24]. For the present study, coding was performed by a single team member, and then verified by the team manager. Two coding approaches were performed in this study. A general coding consisting of the article author information, date of publication, journal of publication and the industry sector based on the 2017 North American Industry Classification System (NAICS) [25]. For articles with a case study application, a more detailed coding procedure was followed. In addition to the previously mentioned generic coding, the more detailed coding included the case study timing, the scope of the case study, the method applied, the geographic information of the researchers performing the case study and of where the case study was performed, the type of indicators used in the study, the type of data source, and finally the application of the case study to the product development process. The coding variables used for the meta-data analysis are summarized in Tables 2 and 3. 
Table 2. Nomenclature of generic coding.

\begin{tabular}{cc}
\hline Coding Variable & Information Being Extracted \\
\hline Full reference & Authors, article title, journal of publication \\
\hline Publication type & Academic journal, roundtable, report \\
\hline Industry sector & $\begin{array}{c}\text { Industry classification based on the 2017 North American } \\
\text { Industry Classification System (NAICS) [25] }\end{array}$ \\
\hline
\end{tabular}

Table 3. Nomenclature of detailed coding.

\begin{tabular}{cc}
\hline Coding Variable & Information Being Extracted \\
\hline Timing & Pre or post study timing \\
\hline Continent of researcher & Continent of researchers conducting the study \\
\hline Continent of case study & Continent where case study is being performed \\
\hline Indicator type & Quantitative, semi-quantitative or qualitative indicators \\
\hline Data source & Primary or secondary data source \\
\hline Application to product development & Applicability of method to the product development process \\
\hline
\end{tabular}

\subsubsection{Research Synthesis Methodology (Meta-Data)}

There are numerous approaches to synthesizing the results from a systematic map. As stated by Zumsteg, et al. [14], "approaches range from qualitative work, such as grouping and summarizing of expert opinions, to quantitative synthesis, in which the published data are adjusted to a common value or other statistical methods are utilized as part of a meta-analysis". Meta-analysis is meant to analyze a large collection of data from individual studies with the purpose of integrating its findings [15]. The meta-data synthesis consisted of two parts. The first part consisted of summarizing the article information using the generic and detailed coding variables already defined. This information was used to create an electronic database that summarizes the information of the selected articles. The second part of the study consisted of a qualitative integration of the articles that included summarizing the challenges of performing social impact assessments identified in individual articles.

\subsubsection{Expected limitations of the Systematic Map}

Instead of focusing on small discipline subsets, the authors wanted to explore social impact assessments across many disciplines, which is one of the reasons why a systematic map was chosen as the method to perform the evidence synthesis, rather than the systematic review. Although the authors want the results to be as generalizable as possible, the breadth of applications of social impact assessments limit this applicability. The results and discussion section only apply to the samples analyzed in this study.

\section{Results}

The systematic mapping allows the identification of the current methods that are available for researchers to perform their assessments, their advantages and disadvantages, and the challenges that users may face when using the methods. A total of 81 articles were selected, of which 49 had a case study application. The results are organized in the following manner. Section 3.1 provides a summary of the articles selected using the systematic map procedure. The articles are classified based on the generic coding presented in Table 2 of the Materials and Methods section. Please refer to Table S1 in the supplementary material for a summary of all of the articles reviewed, along with their generic coding information. The articles that have a case study are classified based on the detailed coding procedure shown in Table 3 of the Materials and Methods section. Please refer to Table S2 in the supplementary material section for a complete summary of the articles reviewed with a case study 
application. Section 3.2 provides a summary of any non-peer-reviewed methods available to perform social impact assessments. Non peer-reviewed methods involve roundtables and collaborations from multiple sources such as private industry experts, academic and university centers, and even representatives from government agencies in some cases. These methods are briefly explained, along with a summary table that presents challenges related to their application. Section 3.3 provides a summary of the identified challenges for the application of social impact assessments. The identified set of 12 challenges are tabulated, along with the articles in which they are mentioned.

\subsection{Systematic Mapping Results}

\subsubsection{Number of Articles Per Year}

Figure 1 shows a plot of the number of articles with respect to their year of publication. As previously mentioned, the recent increase in the number of social impact assessments is attributed to two publications. The first one is the 2009 United Nations Environmental Program (UNEP) and the Society of Environmental Toxicology and Chemistry (SETAC) guidelines [8] for performing social impact assessments. The starting year of 2009 for the inclusion of articles in the systematic map is based upon the year of publication of such guidelines. At this point in time, the field was lacking a major systematic set of guidelines on how to perform a social impact assessment. The UNEP/SETAC guidelines provided a lifecycle-based framework grounded in stakeholder theory.

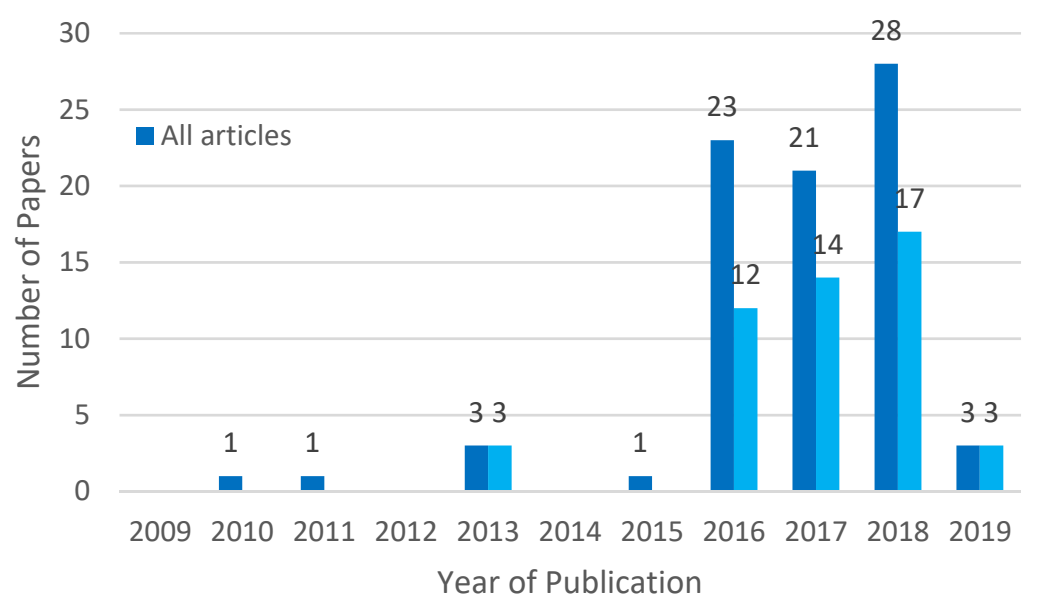

Figure 1. Distribution of articles $(n=81)$ and case studies $(n=49)$ with respect to year of publication.

The guidelines also cover how to collect data and to assess the quality of the data being used for the studies. Although the contribution from the guidelines was significant, there were still a lot of open questions, especially in the selection of the impact subcategories and indicators. In this research, impact indicators are defined as quantifiable metrics that are used to track social impacts based on measurement [26]. Some common examples of indicators are income distribution, occupation injuries and deaths, and access to potable drinking water [27]. The 2013 Methodological Sheets, also from the UNEP/SETAC group, provided additional direction for performing social impact assessments [28]. The publication of these two sets of guidelines resulted in a significant increase in the number of case studies and applications of the guidelines for performing social impact assessments.

\subsubsection{Distribution of Articles in Scientific Journals}

Figure 2 shows the top 4 scientific journals in which the selected articles were published. The results show that a combined $51 \%$ of the selected articles were published in either the International Journal of Life Cycle Assessment or the Journal of Cleaner Production. The high number of articles published in the International Journal of Life Cycle Assessment results from the fact that most of the articles follow a life cycle approach when performing their analysis. The high number of articles 
published in the Journal of Cleaner Production highlights the fact that many social impact assessment studies are complementary to environmental impact studies. In addition, some authors incorporate environmental impacts as part of their social impact assessment analysis.

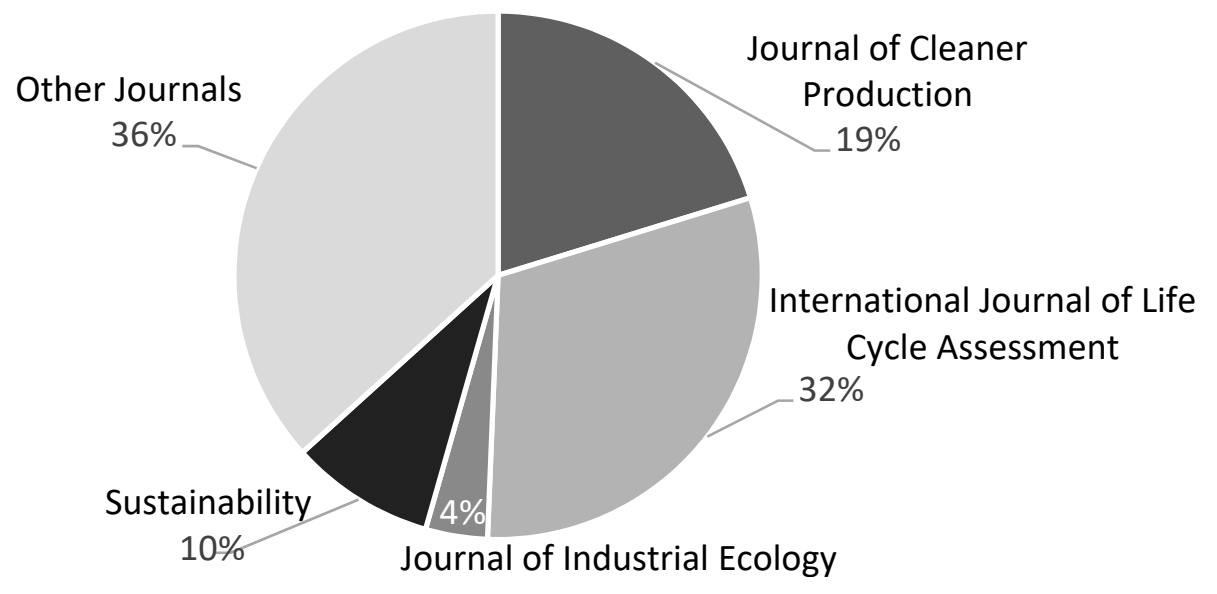

Figure 2. Distribution of scientific journals in which the selected articles were published $(n=81)$.

\subsubsection{Distribution of Industry Sector of Application}

Figure 3 shows the distribution of the selected articles with respect to their industry type. The 2017 North American Industry Classification System (NAICS) was used as a reference for industry classification of the articles [25]. The Agriculture, Forestry, Fishing and Hunting and the Manufacturing industries, are the most represented, contributing to $36 \%$ of the total articles. The Utilities, the Professional, Scientific and Technical Services and the Mining, Quarrying, Oil, and Gas Extraction industries, collectively make up an additional $26 \%$ of the industrial applications. It is interesting to see that a lot of these industries involve a high environmental impact, which highlights the fact that the social impact assessment studies usually evolve as an extension of environmental assessment studies [10].

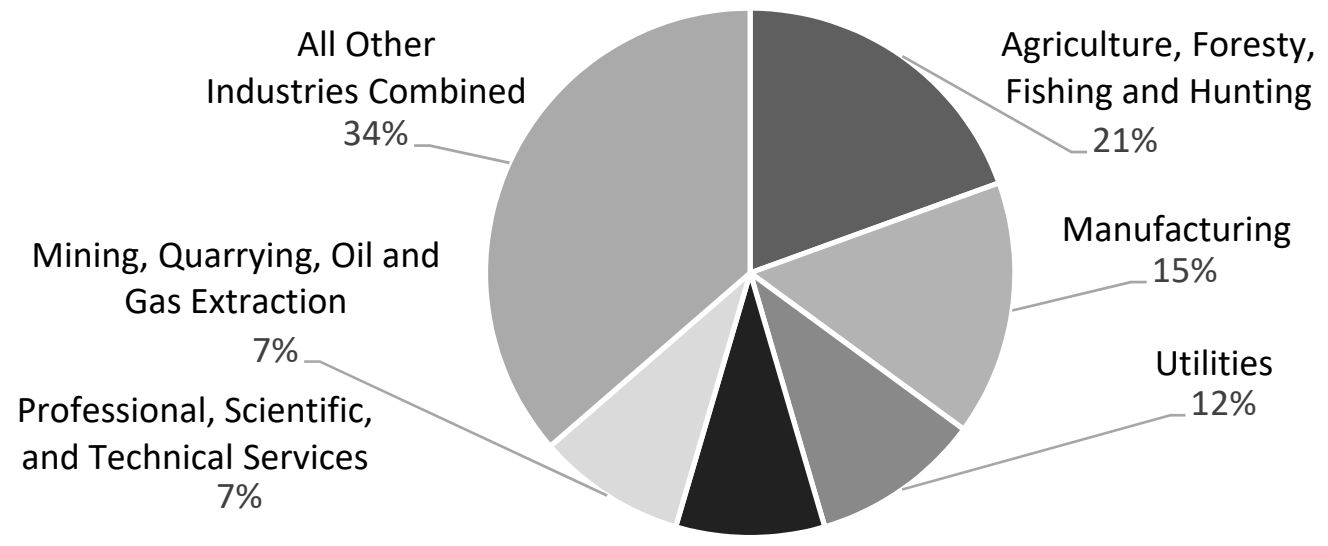

Figure 3. Distribution of articles by industry of application $(n=81)$.

\subsubsection{Case Study Distribution of Industry Sector of Application}

Out of the 81 articles selected using the systematic mapping, 49 have a case study application (for the complete list, please refer to Table 3). Figure 4 shows the distribution of the case studies with respect to their industry classification, based on the NAICS [25]. Similar to all of the articles, the Agriculture, Forestry, Fishing and Hunting sector has the highest representation with $18 \%$. The Manufacturing and Utilities sectors have a similar representation. The top 3 industries collectively represent $48 \%$ of the selected case studies. Contrasted with the previous classification, there is an 
increased representation for the Transportation and Warehousing industry sector, which results from the number of case studies involved with the transportation sector.

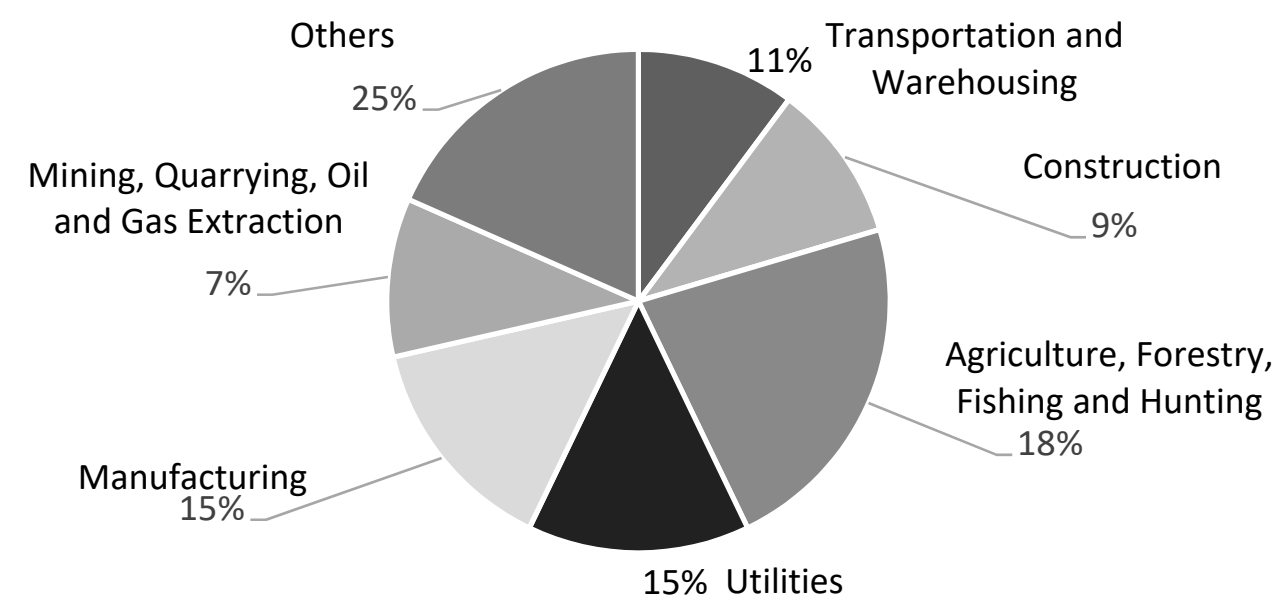

Figure 4. Distribution of case studies by industry classification $(n=49)$.

\subsubsection{Case Study Timing}

Figure 5 shows the timing of the application of the case study shown in the article. As expected, most of the social impact assessments are performed post-implementation, meaning that the product or system being evaluated is already in place. This result was expected, because one of the biggest challenges when performing a social impact assessment is the availability of data. Different from environmental and economic impact assessments, the use of regional data is very important when performing social impact assessments. Due to the globalized nature of current products and services, it can be a big challenge to gather the necessary social data from all companies involved in the different life cycle stages of the products or systems. This procedure is even more complicated at pre-implementation stages, during which the authors do not fully know the companies that will be involved in the product or system. One of the goals of the social impact assessment field is to increase the number of applications at the pre-implementation stage, as this will result in decisions that increase the amount of positive social impacts from products and services. This would be a pro-active approach rather than the currently more common reactive approach.

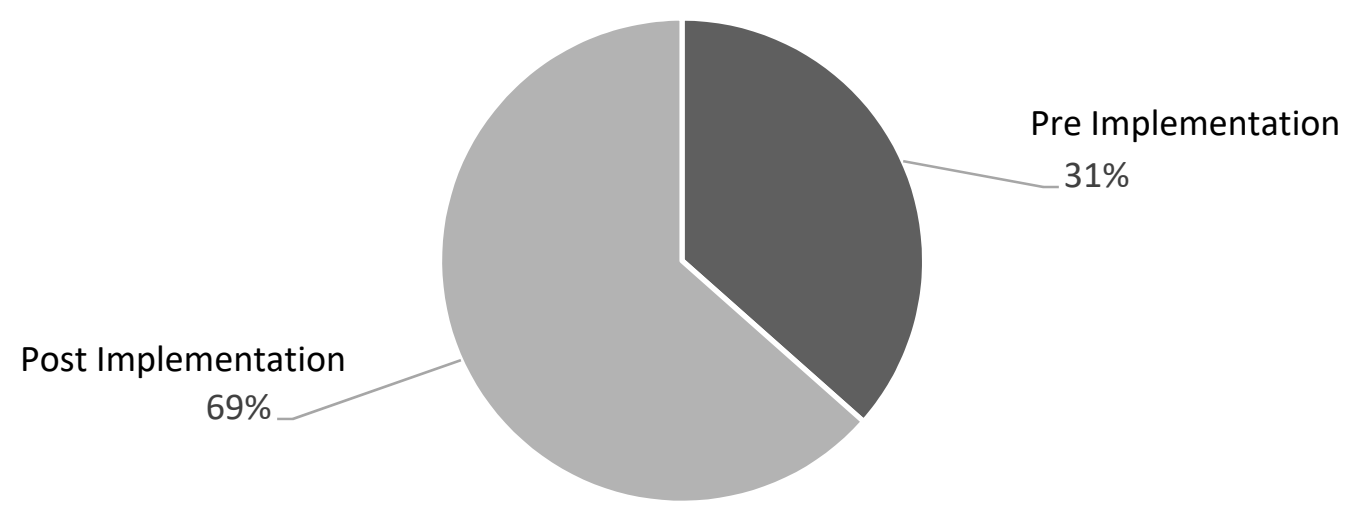

Figure 5. Distribution of the timing of case study performance within articles $(n=49)$.

\subsubsection{Case Study Methodology}

Figure 6 shows that $88 \%$ of the case studies applied a Social Lifecycle Assessment (S-LCA) method when performing the social impact assessment. This shows the fact that most practitioners prefer to follow an LCA approach, which has been the dominant approach to follow when performing environmental assessments. Naturally, if a practitioner performs a social impact assessment as an 
extension of an environmental assessment, an LCA approach would be followed. Out of the LCA percentage, $44 \%$ of the studies follow the 2009 UNEP/SETAC guidelines, showing the significance that publication has had on the field. The fact that only $12 \%$ of the case studies do not follow an LCA approach shows the difficulty of performing social impact assessments.

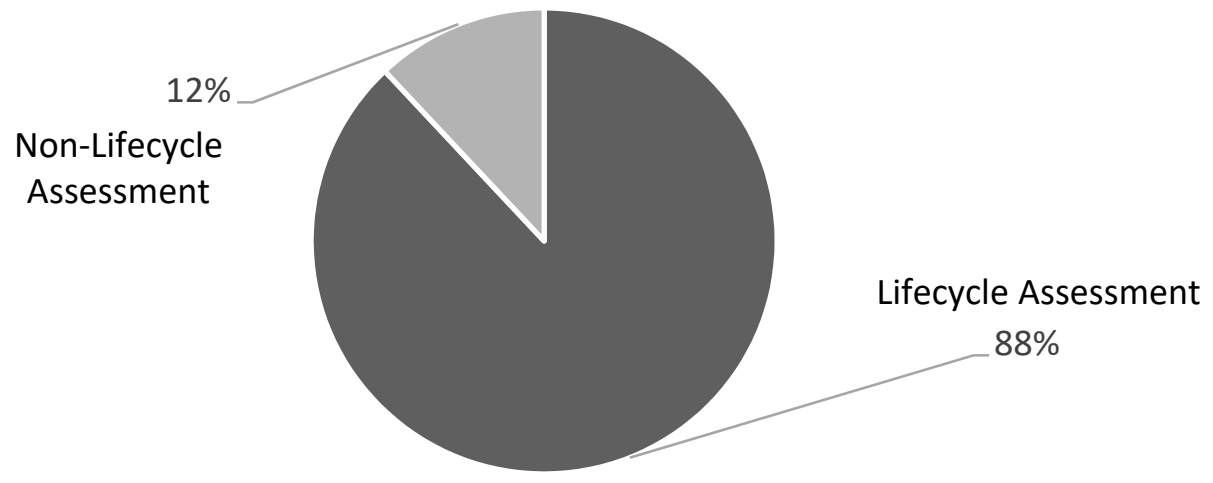

Figure 6. Distribution of the methods applied in our case study $(n=49)$.

\subsubsection{Case Study Continent of Researcher and Continent of Application}

Figures 7 and 8 show the continent of origin of the researchers performing the case studies, and the continent where the case study is being performed, respectively. The American continent has been subdivided into North, Central and South America. This subdivision is based upon two aspects: the significant geographic size of each subdivision, and the significant socio-economic differences that exist among each of them. Figure 8 shows Europe as the leading continent with respect to performing social impact assessment studies, followed by Asia and North America. These three locations combined account for $81 \%$ of all of the case studies. As mentioned in [10], it is interesting to see that most of the case studies are performed by Europe, a continent that has a relatively high quality of living. Numerous reasons are cited for this. Europe has a high concentration of university centers that focus on social impact assessments. In addition, Europe has a well-developed social data infrastructure, which is useful when performing social impact assessments. Continents with less developed economies usually encounter more challenges with regard to the availability of social databases and their data collection infrastructure [12]. Social impact assessment practitioners in the European Union (EU) and the European Economic Area (EEA) should be aware of the changes to personal data management instituted by the European Commission of policies, information and services through the General Data Protection Regulation (GDPR) of April 2016 [29]. The new regulation has been active since 25 May 2018 , and it pertains to the use of personal data such as religious beliefs, sexual orientation or any type of data that would allow the identification of the individual [27].

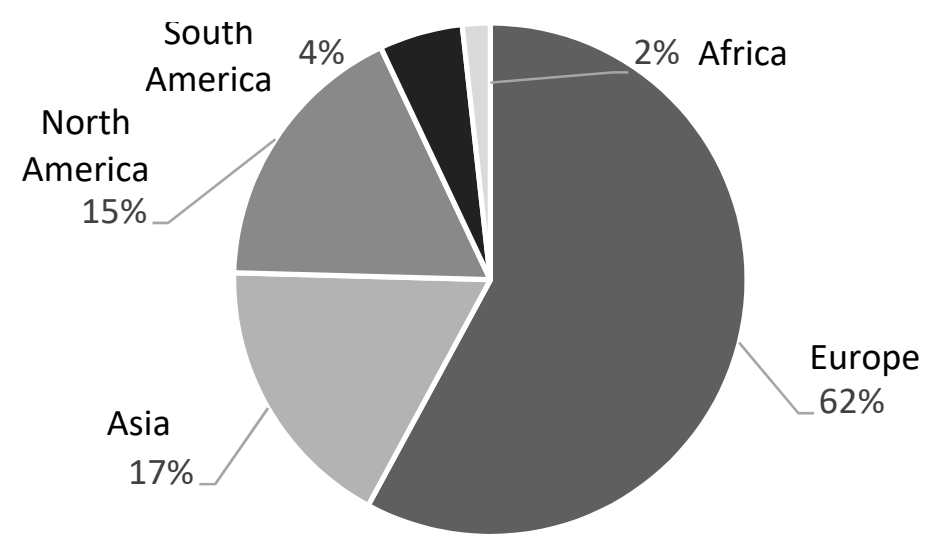

Figure 7. Distribution of the native continent of researcher performing the case studies $(n=49)$. 


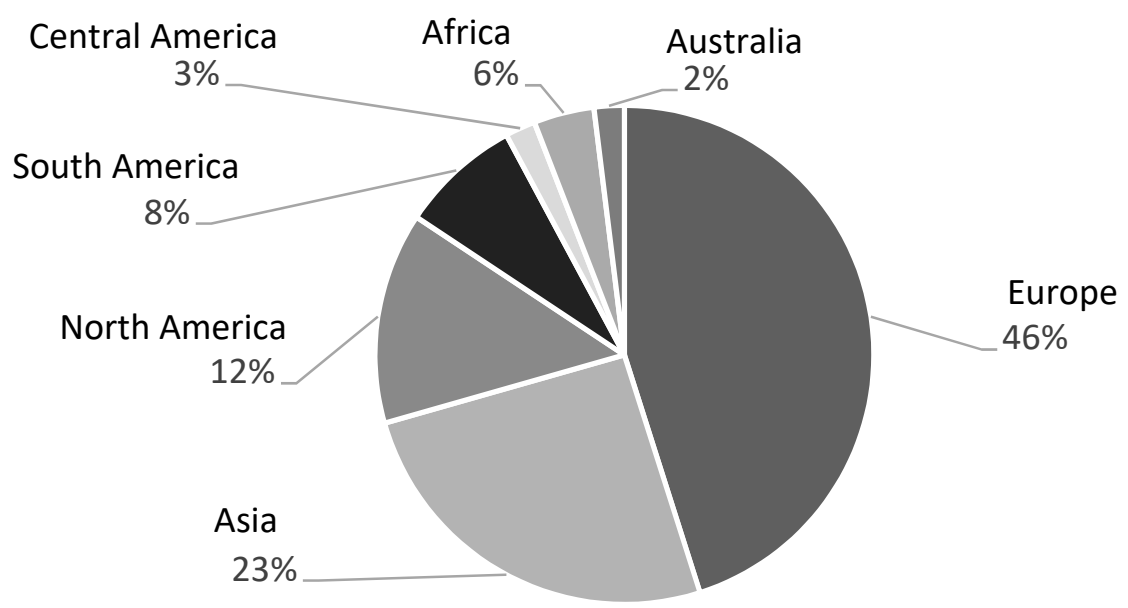

Figure 8. Distribution of continent considered in case studies $(n=49)$.

Figure 8 shows a similar trend to Figure 7 , with the main difference being the fact that there are additional geographical locations considered where the case studies are performed. We see an increase in the African Continent and the appearance of Central America, which was not at all present in Figure 7. The hope is that, as the social impact assessment field progresses as the field matures, the distributions shown in Figures 7 and 8 will be more equally spread on a global scale. Figure 9 shows a visual mapping between the country of the researcher performing the study (red solid dot) and the location of the case study itself (blue solid dot). It shows a global distribution among the case studies, and also how most of the studies originate at the United States, China and from within European countries.

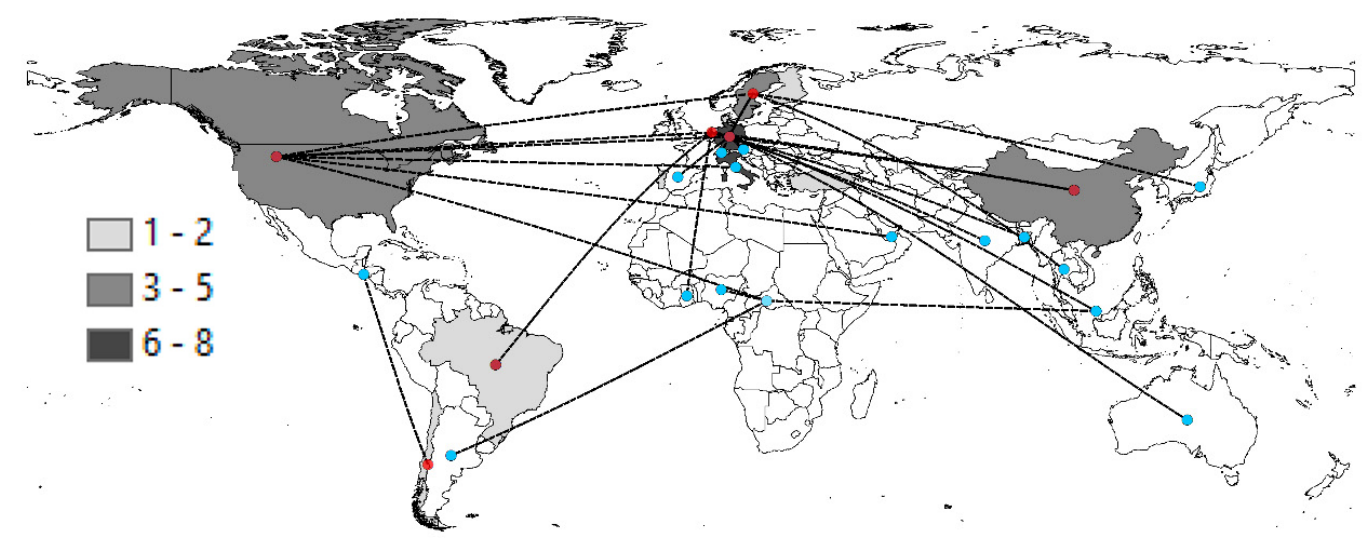

Figure 9. Mapping of the country of the researcher to the country of the case study. Red dots (๑) indicate the locations of the researcher and blue $(\bullet)$ indicates the locations of case studies. Shading levels refer to number of studies originated at that particular country.

\subsubsection{Industry Sector Application by Continent}

Table 4 shows the distribution of the industry sector by continent based on the 49 case studies analyzed. This information allows us to determine which industry sectors are being studied in which countries. Europe has the highest representation of all continents with $59.2 \%$ of all industry sectors, while America and Asia both show a similar representation of $18.4 \%$ and the remaining $4.1 \%$ belongs to Africa. The higher representation of Europe was also found in a previous systematic literature review performed by Petti, et al. [10]. Future research is encouraged in Africa, America and Asia with the hope of achieving an equal representation of all industry sectors at a global scale. 
Table 4. Industry sector share by continent values.

\begin{tabular}{ccccc}
\hline Industry Sector & Africa & America & Asia & Europe \\
\hline $\begin{array}{c}\text { Administrative and Support and } \\
\text { Waste Management and } \\
\text { Remediation Services }\end{array}$ & $0 \%$ & $20 \%$ & $0 \%$ & $80 \%$ \\
\hline $\begin{array}{c}\text { Agriculture, Forestry, Fishing and } \\
\text { Hunting, Transportation and } \\
\text { Warehousing }\end{array}$ & $0 \%$ & $0 \%$ & $0 \%$ & $100 \%$ \\
\hline Construction & $0 \%$ & $14 \%$ & $43 \%$ & $43 \%$ \\
\hline $\begin{array}{c}\text { Management of Companies and } \\
\text { Enterprises }\end{array}$ & $17 \%$ & $33 \%$ & $17 \%$ & $33 \%$ \\
\hline Manufacturing & $11 \%$ & $22 \%$ & $22 \%$ & $44 \%$ \\
\hline $\begin{array}{c}\text { Mining, Quarrying, Oil and Gas } \\
\text { Extraction }\end{array}$ & $0 \%$ & $0 \%$ & $60 \%$ & $40 \%$ \\
\hline Other services & $0 \%$ & $50 \%$ & $0 \%$ & $50 \%$ \\
\hline $\begin{array}{c}\text { Professional, Scientific, and } \\
\text { Technical Services }\end{array}$ & $0 \%$ & $0 \%$ & $0 \%$ & $100 \%$ \\
\hline Transportation and Warehousing & $0 \%$ & $25 \%$ & $0 \%$ & $75 \%$ \\
\hline Utilities & $0 \%$ & $13 \%$ & $0 \%$ & $88 \%$ \\
\hline \% among all industry sectors & $4.1 \%$ & $18.4 \%$ & $18.4 \%$ & $59.2 \%$ \\
\hline
\end{tabular}

\subsection{Non Peer-Reviewed Frameworks and Methods for Performing Social Impact Assessments}

This section provides a summarized description of the identified non peer-reviewed frameworks. A brief description of each framework is presented, along with a summary of its applicability and challenges. Table 5 provides a summary of the frameworks and methods presented in this section along with notable challenges for each.

Table 5. Summary of non-peer-reviewed frameworks for performing social impact assessments.

\begin{tabular}{|c|c|}
\hline Name & Notable Challenges \\
\hline Social Lifecycle Assessment (S-LCA) & $\begin{array}{l}\text { - Lack of standard for indicator list, normalization } \\
\text { of results and results reporting } \\
\text { - Data requirements are high }\end{array}$ \\
\hline $\begin{array}{l}2018 \text { Product social impact assessment (PSIA) from } \\
\text { the Roundtable of Social Metrics }\end{array}$ & $\begin{array}{l}\text { - } \quad \text { No support for aggregation and weighting steps } \\
\text { - } \quad \text { Not suitable for quick screening studies } \\
\text { - }\end{array}$ \\
\hline 2009 UNEP/SETAC Guidelines & $\begin{array}{l}\text { - Not suitable for quick screening studies } \\
\text { - No guidance for the use phase of the lifecycle } \\
\text { - Data requirements are high }\end{array}$ \\
\hline
\end{tabular}


Table 5. Cont.

\begin{tabular}{|c|c|}
\hline Name & Notable Challenges \\
\hline $\begin{array}{l}2013 \text { United Nations Environment Program/Society of } \\
\text { Environmental Toxicology and Chemistry } \\
\text { (UNEP/SETAC) Methodological Sheets }\end{array}$ & $\begin{array}{l}\text { - Lack of guidance on how to perform the } \\
\text { social assessment }\end{array}$ \\
\hline $\begin{array}{l}\text { Prospective Sustainability Assessment of } \\
\text { Technologies (PROSUITE) }\end{array}$ & $\begin{array}{l}\text { - Micro-assessment tool is only applicable to } \\
\text { chemical products } \\
\text { - } \quad \text { Not suitable for screening analysis }\end{array}$ \\
\hline Life Cycle Attribute Assessment (LCAA) & $\begin{array}{l}\text { - } \quad \text { No guidance on the selection of indicators } \\
\text { Results depend heavily on the indicators } \\
\text { selected for the analysis }\end{array}$ \\
\hline $\begin{array}{l}\text { WBCSD Social Lifecycle Metrics for Chemical } \\
\text { Products Guideline }\end{array}$ & $\begin{array}{l}\text { - Only applicable to chemical products } \\
\text { - Use of 5-point scale for results might } \\
\text { be misleading }\end{array}$ \\
\hline Poverty and Social Impact Analysis (PSIA) & $\begin{array}{l}\text { - Interaction between policies are not captured } \\
\text { Data and information constraints, analytical } \\
\text { constraints and time constraints }\end{array}$ \\
\hline Socio-Economic Impact Assessment (SEIA) & $\begin{array}{l}\text { - Level of detail of analysis is determined by the } \\
\text { level of detail of the environmental assessment } \\
\text { - System boundary definition is the same as the } \\
\text { environmental assessment }\end{array}$ \\
\hline
\end{tabular}

\subsubsection{Social Lifecycle Assessment (S-LCA)}

A Social Lifecycle Assessment (S-LCA) is a method that aims to assess the social and socio-economic aspects of products along with their positive and negative impacts throughout their lifecycle, encompassing the extraction and processing of raw materials, manufacturing, distribution, use, re-use, maintenance, recycling and their final disposal $[8,10]$. Research into S-LCA started in the mid-1990s and developed significantly from 2005 [30]. The S-LCA framework can be seen as an extension of an environmental impact assessment, meaning that it has a similar four step structure as stated in the LCA standard ISO 14040: (1) Definition of goal and scope, (2) lifecycle inventory analysis, (3) impact assessment analysis and (4) interpretation of results [8]. The goal of the S-LCA framework is to assess all of the social impacts that a product or service causes for its stakeholders throughout the complete lifecycle of the product, relative to the system of reference defined. Social impacts are understood as the positive and negative consequences on the stakeholders involved in the lifecycle. As seen from the systematic mapping, the S-LCA framework is the one adopted by the majority of authors. Although there has been a significant increase in the number of researchers applying this method, it still faces many challenges, especially in the selection of impact categories and indicators. As a result, a significant number of authors follow the framework in their studies, but the indicators and impact categories are highly varied.

The literature also exhibits a classification among S-LCA studies: Type I and Type II S-LCA studies. This classification is based upon the fact that Type II studies use a causality-based characterization, meaning that there are causal relationships between the input inventory data and the midpoint and endpoint level impacts [31]. Type I S-LCA studies use a Performance Reference Point (PRP) approach to assess the impact data, in which the inventory values are compared to established nominal reference values to determine the magnitude of the impacts, and whether the impacts are positive or 
negative. The results are aggregated into subcategories according to the stakeholder's interest, and the aggregation is performed using a scoring system [31,32].

\subsubsection{Product Social Impact Assessment (PSIA) from the Roundtable of Social Metrics}

The Handbook for Product Social Impact Assessment (PSIA) [33] describes a consensus-based method to assess the positive and negative social impacts of products and services based on the following four stakeholder groups: Workers, local communities, small-scale entrepreneurs and users. The method focuses on assessing the social impacts of products and services, rather than on the impact of the company as a whole. The handbook closely follows the structure of an environmental LCA, as it is aimed to be used by practitioners that want to extend their environmental assessment with the social aspects of the company's products. The roundtable was initiated because the companies recognized the need for a social impact assessment method that is relevant for business. Some of the limitations of PSIA have to do with the amount of data needed to perform the analysis. Also, the results are presented using a 5-point scale, which may be an oversimplification for real-life scenarios. The method does not provide support for performing the aggregation and weighting steps in an impact assessment.

\subsubsection{UNEP/SETAC Guidelines}

The guidelines for a social lifecycle assessment of products [8] provide a set of social and socio-economic LCA-based guidelines to complement the Environmental and Life Cycle costing assessments, contributing to the full assessment of goods and services within the context of sustainable development. The framework follows the structure of the ISO 14040 and ISO 14044 standards for performing environmental LCA.

The guidelines propose a twofold classification of social impacts: By stakeholder categories and by impact categories. On the basis of the most current and state of the art methodological developments, this document formulates guidelines on how to assess a product based on social and socio-economic indicators.

The guidelines are based on stakeholder theory, where impact categories are assigned to each stakeholder category, and inventory indicators and subcategories are assigned to each of those impact categories. The framework presented in the guidelines is based on subcategories, which are socially significant themes or attributes that are classified according to the stakeholder and impact categories; the subcategories are assessed by the use of inventory indicators.

Although their contribution of the guidelines to the social impact assessment field has been significant, they present some significant challenges to the practitioners. The guidelines provide a general framework for performing a social impact assessment, including a set of stakeholders and indicators for each of the social impact categories. However, they are not clear on how to perform an objective selection of the stakeholders and indicators used in the analysis, and on how to normalize or aggregate the results. Another drawback of this method is that it is not developed enough to assess the use phase of the lifecycle.

\subsubsection{UNEP/SETAC Methodological Sheets}

The Methodological Sheets [34] are intended to be used as a complement to the 2009 guidelines when performing the S-LCA. The sheets have been developed recognizing that data collection is the most challenging step when performing a social impact assessment study. Because the sheets are meant to serve as a complement to the 2009 UNEP/SETAC guidelines, these are organized based on the stakeholder categories of workers, local community, society, consumers and value chain actors, under which each corresponding subcategory identified in the guideline is further elaborated. For each stakeholder category, the sheets provide a detailed definition of the stakeholder category, policy relevance of the category, relevant international conventions and agreements, examples of inventory indicators, units of measurements and data sources for generic and specific data analysis. Although the 
sheets provide a vast amount of data for each of stakeholder category, there is still a lack of guidance on how to perform subsequent steps of the assessments.

\subsubsection{Prospective Sustainability Assessment of Technologies (PROSUITE)}

The Prospective Sustainability Assessment of Technologies (Prosuite) [35] aims to deliver a broad life cycle assessment (LCA) framework for the sustainability assessment of existing and new technologies, taking into account the three pillars of sustainability: Economic, environmental and social. The framework is applicable to the evaluation of different technology alternatives and supports policy decision making and future company decisions. It relies on the evaluation of a prospective technology with respect to a reference technology scenario. It is included in this document, as it is one of the few methods that exist to assess prospective technologies. The method has a micro-assessment tool that is intended to be used to perform a social impact analysis regarding the "prosperity" category in the analysis.

However, the micro-assessment tool is only applicable for chemical plants; the prosperity analysis must be performed manually for other products and services. Another limitation of the PROSUITE method is that the analysis takes a significant amount of time, which means that it is not suitable for performing a screening or low detail analysis, unless some parts of the analysis are omitted.

\subsubsection{Life Cycle Attribute Assessment (LCAA)}

The Life Cycle Attribute Assessment (LCAA) [36] method summarizes attributes of processes along a product's life cycle or company supply chain by means of certification of process attributes.

The method builds on the theoretical structure of LCA to construct a supply chain model and aims to enable local, site-specific evaluation results (i.e., SA 8000, ISO 14001, Fair Trade Certification) to be integrated into LCA. The method provides a link between the LCA and Corporate Social Responsibility (CSR) methods [37], by determining what percentage of a product's supply chain has a particular attribute.

The method does not provide any guidance for the selection of indicators when performing the attribute calculation, meaning that the indicators used depend heavily on the user.

\subsubsection{WBCSD Social Lifecycle Metrics for Chemical Products Guideline}

The Social Lifecycle Metrics for Chemical Products Guideline provides guidance and social lifecycle metrics that enable companies to assess and report on the social impacts of chemical products within the full value chain, by means of a life cycle approach [38]. This method is inspired mainly by the 2009 UNEP/SETAC Guidelines [8] and the 2014 Handbook for Product social impact assessment [33]. The method relies on 25 selected social topics that are divided into two groups: 11 mandatory social topics, and 14 non-mandatory social topics. The results are presented on a 5-level reference scale from -2 (unacceptable) to +2 (outstanding) via 0 (standard compliance). The framework was included in this summary, as it is applicable to products from the chemical industry specifically.

However, the method still presents some significant challenges to the user. The use of a 5-point scale might be misleading when reporting the final results. Also, the analysis is very elaborate and data-intensive, meaning that it is not suitable for performing screening or low-detail studies.

\subsubsection{Poverty and Social Impact Analysis (PSIA)}

Poverty and Social Impact Analysis (PSIA) involves the analysis of the distributional impact of policy reforms on the well-being of different stakeholder groups, with a particular focus on the poor and vulnerable [39]. The framework aims at understanding the impact of policy changes by evaluating policy impacts individually to understand the overall effect of a group of reforms. Now that poverty has been recognized as a multidimensional issue, social indicators are now used in its analysis, in addition to economic indicators.

PSIA assumes that policy impacts will affect the welfare of communities through five channels: Employment, prices (production, consumption, and wages), access to goods and services, assets and 
transfers and taxes. It is expected that single policy reform will affect more than one channel. One of the main challenges with performing PSIA is understanding long-term policy effects based on short-term information, because policy impacts take time. In addition, the effects of policy impacts will depend upon the stakeholders, as each has different circumstances, but are impacted by the same policy reform. Because policy reforms are evaluated individually, the interaction effects between the policies are not captured.

\subsubsection{Socio-Economic Impact Assessment (SEIA)}

Socio-Economic Impact Assessment (SEIA) is a systematic method used during environmental impact assessment to identify and evaluate the potential socio-economic and cultural impacts of a proposed development on the lives and circumstances of people, their families and their communities [40]. Impacts are defined as changes caused directly or indirectly by industrial development activities. SEIA tends to focus on avoiding detrimental social impacts caused by industrial development activities, and also to plan for maximizing the benefits of such activities. The method is a complement to performing an environmental impact analysis, and it focuses on identifying, assessing, mitigating and monitoring the potential socio-economic impacts of a proposed development.

One of the weaknesses of SEIA is that the boundaries of the system being analyzed are the same as the ones used for the environmental impact assessment. This approach might affect the completeness of the analysis, because social impacts usually extend further than environmental impacts.

\subsection{Determination of Challenges from Systematic Map}

The systematic map protocol enables a detailed understanding of current social impact assessment methods, and can also reveal gaps that are present in the field. The determination of such gaps allows the researcher to determine important aspects of the research, such as the relevant areas of the contribution of the research or the main barriers that are preventing the field from advancing. For the social impact assessment field, a number of challenges were identified from the selected articles. Table 6 provides a summary of the challenges identified in the social impact assessment field, along with the reference articles in which each of the challenges are mentioned. This list of challenges is described in detail in Section 4.2.

Table 6. Summary of challenges when performing social impact assessments.

\begin{tabular}{|c|c|c|}
\hline Challenge & Explanation & Related Articles \\
\hline 1 & $\begin{array}{l}\text { Determination of what social impacts to consider and how to } \\
\text { quantify them }\end{array}$ & {$[1,13,41]$} \\
\hline 2 & $\begin{array}{l}\text { Uncertainty with indicator selection, normalization, aggregation, } \\
\text { and weighting }\end{array}$ & [42-51] \\
\hline 3 & Determination of whether a functional unit should be used & {$[11,51-55]$} \\
\hline 4 & $\begin{array}{l}\text { Determination of minimum criteria to be satisfied during data } \\
\text { collection efforts }\end{array}$ & {$[34,49,56]$} \\
\hline 5 & Allocation of social impacts into different categories & {$[49,56-58]$} \\
\hline 6 & $\begin{array}{l}\text { Connection of social impacts with products rather than with the } \\
\text { conduct of companies producing the products }\end{array}$ & {$[59,60]$} \\
\hline 7 & Definition of "social well-being" used in the analysis & {$[44,54,61-64]$} \\
\hline 8 & $\begin{array}{l}\text { Selection of a preferred method to perform the social impact } \\
\text { assessments }\end{array}$ & {$[4,31,51,59,65]$} \\
\hline 9 & Definition of the system boundaries & {$[13,32,53,57,66,67]$} \\
\hline 10 & Selection of global or location specific data & {$[50,56,59,68]$} \\
\hline 11 & Selection of scoring scales for reporting the results & {$[34,39,50,60,69-71]$} \\
\hline 12 & Selection of stakeholders relevant to the study & {$[39,40,56,57]$} \\
\hline
\end{tabular}




\section{Discussion}

\subsection{Discussion of Selected Articles}

A summary of articles that used literature reviews to investigate challenges and future research direction for social impact assessments is shown in Table 7. As with the rest of the selected articles, most of these focus their literature review on the S-LCA methodology. The majority of these studies focus on the methodological weaknesses of S-LCA [10], such as the selection of impact criteria and indicators $[5,11,30]$, identification of the system boundaries [48], the selection of inventory data, characterization and the weighting method used [32]. Two articles focus on the use of a systematic review to determine future research areas of research in S-LCA $[49,50]$.

Table 7. Summary of previous systematic review articles.

\begin{tabular}{|c|c|c|}
\hline Reference & Year & Issue Investigated \\
\hline [30] & 2018 & Selection of impact criteria and indicators \\
\hline [49] & 2018 & $\begin{array}{l}\text { Use of automatic text analysis to determine state of the art } \\
\text { and future research direction }\end{array}$ \\
\hline [48] & 2018 & $\begin{array}{c}\text { Identification of the system boundaries and areas of needed } \\
\text { developments }\end{array}$ \\
\hline [11] & 2017 & $\begin{array}{l}\text { Identification of issues with indicators across industries. } \\
\text { Authors synthesize a list of indicators as a step towards } \\
\text { standardization. }\end{array}$ \\
\hline [10] & 2018 & $\begin{array}{l}\text { Weaknesses of Social Lifecycle Assessment (S-LCA) by } \\
\text { means of case study analysis }\end{array}$ \\
\hline [5] & 2018 & Identifications of social impacts of products \\
\hline [32] & 2018 & $\begin{array}{l}\text { Exploration of type I S-LCA methods with a focus on } \\
\text { inventory data, aggregation, characterization and weighting } \\
\text { methods }\end{array}$ \\
\hline$[50]$ & 2018 & $\begin{array}{c}\text { Analysis of the main issues affecting S-LCA with a focus on } \\
\text { the automotive sector }\end{array}$ \\
\hline
\end{tabular}

Because of its wide implementation, methodological issues with the LCA framework have been highlighted by numerous authors outside of the social impact assessment field [15,51,52]. This is why a lot of the challenges mentioned by the authors are also present in environmental LCAs. Based on the systematic map results, the majority of authors use a social impact assessment methodology that is LCA-based. It should then be no surprise that a lot of these challenges are mentioned by the authors when performing social impact assessments using S-LCA. Although most articles follow an LCA approach, the methodology being implemented is modified based on the application being analyzed. This becomes a significant challenge when attempting to propose a standard methodology that is appropriate for most applications. Among the LCA studies, the 2009 UNEP/SETAC guidelines had a strong presence, where $44 \%$ of the case studies cite them as a source of information with regards to the stakeholder groups, impact categories and indicators. Another important observation regarding LCA studies is that $79 \%$ performed a "cradle to gate" analysis while $21 \%$ performed a "cradle to grave" analysis, which is expected, due to the higher level of complexity present in the "cradle to grave" analysis.

The case studies were evaluated with regards of the scope of the study, i.e., the purpose of performing the social impact assessment. The case studies were classified according to the following categories adopted from the work of Kjaer, et al. [53]: Comparison, informative or enhancement scope. Table 8 shows the question being addressed by each of the study scopes. The comparison scope aims to evaluate the social impacts among different alternatives. Thirty-six percent (36\%) of the case studies had a comparison scope. The informative scope assesses the social impacts resulting from 
the implementation of the system being studied. Fifty-six percent (56\%) of the case studies had an informative scope. The enhancement scope aims to determine how the system implemented can be enhanced. Only $8 \%$ of the case studies had an enhancement scope. These results show that most social impact assessments are focused on having an understanding of the social impacts of the system and on how the selection of different alternatives affects these impacts.

Table 8. Study scopes identified in case studies.

\begin{tabular}{cc}
\hline Study Scope & Question Addressed \\
\hline $\begin{array}{c}\text { Comparison } \\
\text { Informative }\end{array}$ & What are the social impacts among different alternatives? \\
Wnhancement & What are the social impacts of the system, and how can it be \\
enhanced?
\end{tabular}

Although access to data is recognized as one of the most difficult aspects of performing a social impact assessment, $96 \%$ of the case studies relied upon data for performing their analysis, while only $4 \%$ relied on the use of modeling. Among those that used data, $50 \%$ used a combination of primary and secondary data sources, $30 \%$ used primary data only, and $20 \%$ used secondary data only. Regarding the type of indicator used in the case studies, $56 \%$ use quantitative indicators, $24 \%$ use qualitative indicators and $20 \%$ use semi-quantitative indicators.

Table 9 shows a summary of the databases used in the case studies. The databases were classified based on the following three categories: Global or International Agreements, Standards or Handbooks, Sustainability Frameworks and Country or Economic Sector Guidelines. The number of databases highlights the difficulty in achieving a generalization of data among different social impact studies, as there is usually no agreement among the data reporting infrastructure within them. This is one of the biggest roadblocks towards achieving standardization among the social impact assessment methodology. Before deciding whether or not standardization is the best approach, one must carefully balance the risk of losing local context with the risk of achieving a standard method.

Table 9. Information databases used in the case studies. (Where ISO refers to the International Organization for Standardization).

\begin{tabular}{|c|c|}
\hline Category & Database Name \\
\hline $\begin{array}{c}\text { Global or International Agreements, Standards } \\
\text { or Handbooks }\end{array}$ & $\begin{array}{ll}\text { - } & \text { World Mineral Statistics Datasets } \\
\text { - } & \text { Social Hotspot Database } \\
\text { - } & \text { Global Reporting Initiatives (GRI) } \\
\text { - } & \text { ISO 26000 } \\
\text { - } & \text { ISO } 140412-1: 2008 \\
\text { - } & \text { International Reference Life Cycle } \\
\text { - } & \text { Data (ILCD) Handbook } \\
\text { - } & \text { Intergovernmental Panel on Climate Change } \\
\text { - } & \text { IIPCC) Organization for Economic Development } \\
\text { - } & \text { GRI's G4 sustainability reporting guidelines } \\
\text { - } & \text { United Nations Development Program } \\
\text { - } & \text { International Standard Industrial Classification } \\
\text { - } & \text { Institute for Employment Research (IAB) }\end{array}$ \\
\hline
\end{tabular}


Table 9. Cont.

\begin{tabular}{|c|c|}
\hline Category & Database Name \\
\hline Sustainability Frameworks & $\begin{array}{ll}\text { - } & \text { Social progress Index } \\
\text { - } & \text { Sustainable Society Index } \\
\text { - } & \text { 2009 UNEP/SETAC Guidelines } \\
\text { - } & \text { Sustainability Appraisal in Infrastructure } \\
\text { - } & \text { Projects (SUSAIP) } \\
\text { - } & \text { 2013 Methodical Sustainability Index (TSI) } \\
\text { - } & \text { Sustainability Assessment of } \\
& \text { Agriculture Systems }\end{array}$ \\
\hline Country or Economic Sector Guidelines & $\begin{array}{ll}\text { - } & \text { Hong Kong Business Environment } \\
\text { - } & \text { Council Limited } \\
\text { - } & \text { Brazilian Institute of Geography and Statistics } \\
\text { - } & \text { Ministry of Labor and Employment and } \\
\text { - } & \text { Ministry of Social Security } \\
\text { - } & \text { Chinese Core Life Cycle Database } \\
\text { - } & \text { Organization for Economic Cooperation } \\
\text { - } & \text { US Executopentive Order 13514 } \\
\text { - } & \text { US Advanced Manufacturing Cluster } \\
\text { - } & \text { US Bureau of Economic Analysis Data } \\
\text { - } & \text { North American Industry Classification System } \\
\text { (NAICS) }\end{array}$ \\
\hline
\end{tabular}

Table 10 shows a summary of the articles based on the type of impacts being analyzed in each of them. The majority of articles ( $75 \%$ ) focus on evaluating socioeconomic impacts, which is expected, since most of the articles apply the UNEP/SETAC Guidelines [8] framework, in which socioeconomic impacts are the focus. Eleven percent (11\%) of articles perform the analysis based on the three-dimensional sustainability approach, which states that sustainability is composed of an economic, environmental and social dimension. A combined social and environmental focus was the least common in the selected articles, with only a 5\% share. Nine percent (9\%) of the articles were classified as using a "Novel Approach", meaning that the authors present a methodology that is not based on the typical impact assessment approach that is presented on the UNEP/SETAC guidelines. The authors adopt methodologies from other disciplines to perform the sustainability evaluation. Reitinger et al. [54] use the capabilities approach from philosophy to define the impact categories used in their analysis. Bianchi et al. [55] propose a social evaluation of energy systems based on the following five equity definitions: Social equity, spatial equity, intergenerational equity, procedural equity and structural equity. Janker et al. [56] perform a social assessment of an agricultural system by combining Parson's social system of change and Maslow's hierarchy of needs. These are novel approaches, and they show that authors are researching methodologies outside of the typical areas to complement what is already existing in the literature. 
Table 10. Summary of the approaches used for sustainability assessment.

\begin{tabular}{ccc}
\hline Assessment Type & Share of Articles & Reference of Article \\
\hline Socio-economic assessment & $75 \%$ & {$[6,8,27,31,33,41,45,47,50,57-88]$} \\
\hline $\begin{array}{c}\text { Social, economic and } \\
\text { environmental }\end{array}$ & $11 \%$ & {$[89-94]$} \\
\hline Novel approach & $9 \%$ & {$[54-56,95,96]$} \\
\hline Social and environmental & $5 \%$ & {$[44,97,98]$} \\
\hline
\end{tabular}

\subsection{Discussion of Identified Challenges}

A total of 12 challenges were identified by reviewing the selected articles. Each of the challenges is explained in more detail in the following subsections.

\subsubsection{Challenge \#1: Determination of What Social Impacts to Consider and How to Quantify Them}

Part of the issue with the determination of social impacts is that there are varying definitions of what social impacts are, and what should be considered a social impact. As pointed out in Grijalva et al. [41], "The categorizations of social performance measures presented in the literature vary greatly, resulting in non-uniform assessments in practice. There is a need for a standardized assessment tool that is generalizable and accessible to all industries". This issue is also raised by Vanclay [99], where a review of existing lists of social impact variables are "found to be inadequate and contradictory".

Vanclay established that social impacts influence "an actual experience of an individual or community." [99]. Another issue with social impacts is the fact that the evaluation of social impacts may be seen as subjective by the different stakeholders, which is further exacerbated by the lack of a standard code of practice when performing SIA [49].

4.2.2. Challenge \#2: Uncertainty with Indicator Selection, Characterization or Normalization, Weighting and Aggregation

Uncertainty is present at many stages of SIA. The first step of performing any type of impact assessment is the selection of the indicators that would make up the inventory analysis. The inventory of the indicators determines what data needs to be collected to perform the assessment. Depending on the approach selected for performing the impact assessment, the practitioners would select the indicators for a predetermined list, or in other cases, the authors aim at developing their own set of indicators. As stated by Zanchi et al. [50], "a robust approach for indicators' selection is seldom discussed and reported in a transparent way". SIA studies use different types and numbers of social indicators, which has motivated authors to propose methods of developing social indices and indicators [82].

Once the data for each of the indicators have been selected, the next step is to normalize the values. The normalization step aims at allowing for the comparison of different impact categories that have very different numerical scales. A typical approach is the use of Performance Reference Points (PRP), which are reference values used to scale the results based on global or context-specific data values. Siebert et al. [47] raises the fact that there is no standard characterization method yet in SIA, and they propose the RESPONSA framework. The RESPONSA framework is a characterization approach that "generates context-specific PRP", which can effectively reflect the social conditions influencing the various organizations involved in producing a specific product.

The weighting step is required to perform the aggregation of the resulting normalized values. In order to allow for the comparison of different sustainable alternatives, the results are often aggregated into a single score that represents the "sustainability level" of the design alternative being considered [35]. The weighting step assigns importance levels to the results before performing the aggregation of the results. The methods used to establish the weights vary significantly, and is thus a source of uncertainty in the final results. In addition, the method used to perform the aggregation also 
varies among different studies, which is another source of uncertainty when comparing the results of different social assessments.

\subsubsection{Challenge \#3: Determination of Whether a Functional Unit Should Be Used}

As per the Internal Standard for Environmental Life Cycle Assessment ISO 14040 [100], the functional unit is defined as "a measure of the performance outputs of the product systems". The document also explains that the functional unit provides a reference to which inputs and outputs are related, a necessary feature to ensure compatibility and comparability among different LCA studies. Different from an environmental LCA, social impact assessments deal with a higher level of qualitative indicators that are not tied to a product functional unit. The inclusion or not of a functional unit could be affected by numerous factors, such as the scope of the analysis, the relevance of the process, the product system scheme [49], and even the system boundary definition [31]. As stated in Siebert et al. [44], a review performed by Petti et al. [10] indicates that "out of 35 social LCA case studies, only 12 took a numerical unit into account, whereas 18 considered the use of a non-numerical functional unit and 5 stated no functional unit at all". In the cases in which the social assessment is performed as an extension to an environmental LCA, along with the same system boundary definitions, it is recommended to use the same functional unit for the two analyses. Other studies, such as Umair et al. [101], consider qualitative data, and they emphasize that it is not possible to express the impacts using a functional unit.

\subsubsection{Challenge \#4: Determination of Minimum Criteria to Be Satisfied during Data Collection Efforts}

Data collection is a crucial component of performing social impact assessments, and it has been recognized that "data collection can benefit from improved standardization and integration with social sciences" [41]. It is often regarded as the most difficult and time intensive part of the study [38]. Data sources are divided into primary and secondary data sources. Primary data sources refer to data collected directly from the companies or institutions being studied. Secondary data sources refer to databases of collected data at the country or sector level, such as the Social Hotspot Database [46] or the Product Social Impact Life Cycle Assessment (PSILCA) database [102]. Certain frameworks, such as the Product Social Impact Assessment (PSIA) [33], recognize the importance of data quality when collecting data and recommend the use of a data quality matrix to assess the quality of the collected data.

\subsubsection{Challenge \#5: Allocation of Social Impacts into Different Categories}

The use of indicators when performing a social impact assessment involves their classification into different groupings called impact categories. Let us take as an example the PROSUITE framework for performing sustainability assessments of prospective technologies [35]. The sustainability assessment consists of an aggregated analysis of the following five impact categories: Impact on human health, impact on social well-being, impact on prosperity, impact on the natural environment and impact on exhaustible resources. To determine the impact at each category, a group of indicators is assigned to each of the impact categories. The grouping of indicators and social impacts into different impact categories can be a source of uncertainty, since there is no single, standard methodology to perform such a classification. This process is further complicated when direct links between indicators and social impacts are such a big issue in social impact assessments [42].

4.2.6. Challenge \#6: Connection of Social Impacts with Products rather than with the Conduct of Companies Producing the Products

Evaluating the social impact of a product involves the evaluation of social conditions along the production and supply chain of a product. A practitioner performing a social assessment of a product may want to focus on the companies involved with producing such a product. In this case, the social impacts of the product would be determined by the conduct of the companies producing the product 
and the score they get in the set of indicators being evaluated rather than on the product itself [45]. The social assessment might not differentiate much between different products whose companies have similar social information within them [33]. This presents a significant challenge when a group of designers is evaluating the different design alternatives of a product, and the process of selecting the more socially sustainable alternative becomes a matter of the conduct of companies rather than of the technical specifications of the product itself.

\subsubsection{Challenge \#7: Definition of "Social Well-Being" Used in the Analysis}

The World Health Organization (WHO) recognizes that there is no universal definition of social well-being, as it may have different connotations for different individuals [103]. Hasster et al. [75] summarize different definitions of well-being found in the literature: "For instance Keyes [104] defines social well-being as the appraisal of one's circumstance and functioning in society, while the USIP [105] defines it as an end state in which basic human needs are met and people are able to coexist peacefully in communities with opportunities for advancement". But why is the definition of social well-being so important? And how is it connected to products and services, when there is a lack of well-documented impact pathways between inputs and social impacts [32]? The definition of social well-being used in the social assessment should always be important, since the goal of performing social assessment is to minimize any detrimental impacts on stakeholders. The definition becomes especially important when using frameworks that have social well-being as part of their analysis, such as the PROSUITE framework.

\subsubsection{Challenge \#8: Selection of a Preferred Method to Perform the Social Impact Assessments}

While there are many S-LCA approaches available in the literature, there is a lack of a standard method to be agreed upon, and a lack of assessment priorities $[3,45]$. There is not yet any common list of social impact indicators that have been agreed upon in the field [30]. Having an agreement on a global list of indicators and an assessment method will aid in the standardization of performing social assessments, and in the ability to compare the results from different studies.

\subsubsection{Challenge \#9: Definition of the System Boundaries}

System boundaries define which inputs and processes are included in the social assessment. System boundaries will also define the data that needs to be gathered to perform the assessment, as it will determine the list of indicators to be used in the study. The definitions of the system boundaries found in the literature are numerous. Some studies define similar system boundaries as the environmental LCA, while others attempt to consider the full life cycle of the product, but ignore the processes that do not substantially influence the overall outcomes of the study [31]. The lack of a standardized method to define the boundaries of the analysis complicates the process of comparing results from different social assessments.

\subsubsection{Challenge \#10: Selection of Global or Location Specific Data}

Different from environmental and economic impact assessments, the use of local data is essential in most social impact assessments. Some social impact assessments are performed only for screening purposes, using country or sector level data to detect areas of crucial improvement [46]. When performing a more detailed analysis, the use of local data is recommended, but there are still challenges present during the data collection stage with regards to financial and temporal resources, or even data availability. The decision to use global or local specific data is very important, and will affect the results of the social impact assessment. 


\subsubsection{Challenge \#11: Selection of Scoring Scales for Reporting the Results}

There is currently no general standard for interpreting the results of Performance Reference Points (PRP) social impact assessments. As stated by Siebert et al. [47] "However, a characterization approach, based on a context-specific benchmark which is easy to understand and interpret, is still missing. In general, characterization approaches provide meaning to social indicator values (i.e., the inventory data). However, there is no standardized S-LCA characterization method yet". The variety of numerical scales used to report the results from social impact assessments are proof of the lack of a standard to report the results. As shown by Singh et al. [83] "While Hosseinijou et al. [85] have taken a 6-point scale with values ranging from 0 to 9, Foolmaun and Ramjeeawon [106] have gone for a 5-point scale with values ranging from 0 to 4 . For this study, a 4-point scale having values ranging from 1 to 4 is proposed, with scoring 1, 2, 3 and 4 representing highly negative, negative, neutral and positive impact, respectively, as perceived by the individual respondents. The selection of a 4-point scale has been made to establish a reasonable balance between the ease of responding and adequate granularity in the results". Other frameworks such as PSIA and Social Lifecycle Metrics for Chemical Products Guideline use a scale from -2 to $+2[33,38]$.

\subsubsection{Challenge \#12: Selection of Stakeholders Relevant to the Study}

The use of stakeholder theory is significant in a number of frameworks found in the literature. Because the 2009 UNEP/SETAC was such a significant source of inspiration for social impact assessments performed after the publications, the use of stakeholder theory is very common in case studies and frameworks developed after their publication; these include, but are not limited to, WBCSD Social Lifecycle Metrics for Chemical Products Guideline, Poverty and Social Impact Analysis and the Product Social Life Cycle Assessment (PSILCA) Database [38,39,102]. The selection of stakeholders is crucial, as this determines the individuals and communities that are included within the system boundaries; in other words, it determines who will be included in the analysis. Part of the challenge when performing social impact assessments is the fact that social impacts can be more far-reaching than environmental and economic impacts, and their inclusion in the analysis needs to be balanced with the resources available to perform the study.

\section{Conclusions}

Progress in the field of social impact assessments is essential to achieve better informed decisions with respect to the topic of social impacts and social sustainability. The higher number of published articles and grey literature related to social impact assessments in recent years shows increased interest in the improvement of social aspects, resulting from product development and public policy decisions. Social impact assessments play a significant role in achieving global sustainability goals by complementing the results of environmental and economic assessment methods. In order to contribute to the development of socially sustainable practices, the purpose of this study was to develop a detailed understanding of the field by collecting and analyzing published material related to social impact assessments. Additionally, the selected articles allowed the identification of a set of fundamental challenges present when implementing social impact assessments. By means of a systematic mapping process, 81 articles were selected through an online database search, from which 49 of these had a case study application. Additionally, eight grey literature documents consisting of frameworks and roundtables were included in the process of identifying the challenges present when performing social impact assessments. The articles have been categorized by means of a generic and detailed description, shown in Tables S1 and S2 of the supplementary material. The coded information has been organized in an electronic database file for the interested reader.

The selected articles and grey literature data highlighted the high variability of procedures and methods that exist in the literature to perform social impact assessments. All industry sectors (based on the 2017 NAICS) are represented at some level in the selected articles, with agriculture, manufacturing 
and utilities having the highest representation. LCA-based methods are the preferred choice among the selected articles, although significant variations are performed based on the characteristics of the application. Results show that most social impact assessment studies aim to evaluate the social impact of the system for informational purposes, followed by the comparison of different alternatives of the system with regard to their social impacts.

The systematic mapping also allowed for the identification of a set of recurring challenges that practitioners face when performing social impact assessments. A lot of these challenges are also seen in the field of E-LCA [51,52], and this should be no surprise, as most of the studies selected in the systematic map are based upon the S-LCA framework. It seems that in addition to the challenges already identified in E-LCA, social impact assessments add an additional level of difficulty. The 12 challenges identified by means of the systematic map should serve as a reference for future research areas to ease the implementation of social impact assessments. Although there is an increased interest from the scientific community in the field of sustainability and social impact assessments, there is still a lack of implementation by private companies of such methods. Assuming the companies are interested in understanding the social impacts of their product decisions, it might be challenging to incorporate social impact assessments into their already complicated product development process. One of the sub questions of the systematic map aimed at determining which of the articles presented a method that is applicable to the product development process.

Of the selected articles, only $9 \%$ had a product development application, which shows a need for developing methods that are more applicable in this aspect. More significant is the fact that there are not any practical methods and tools to a perform sustainability assessment during the early stages of designs [91].

The contributions from this article are divided into the following three areas: Scientific, industry and social contributions. A scientific contribution is achieved by developing detailed knowledge of the social assessment field and creating a classified database of the methods available. An industry contribution is being made by the identification of a set of challenges that are complicating the implementation of social impact assessments. By identifying these challenges, future research efforts should focus upon developing solutions that ease the application of social assessments from a company standpoint. A social contribution is achieved by providing future research areas of focus that will allow for an easier implementation of social impact assessments. Easier implementation results in better informed decisions that are translated to the community through more socially sustainable products and services. This study aims to help both social impact practitioners and researchers to better understand what the critical issues are in the field of social impact assessment.

The role of social impact assessment is critical towards the goal of improving the economic, environmental and social sustainability of communities at a global scale. The future of social sustainability should focus on incorporating knowledge from other disciplines, such as social sciences, where social impacts are evaluated from a more qualitative perspective, relative to the quantitative approaches used in engineering. Incorporation of stakeholders is recommended regardless of the system boundary definition of the studies. Stakeholder input may be incorporated at all stages of the social impact assessment, but specially during the early stages of the analysis when the study scope and system are being defined. Future research efforts should focus on simplifying the process of performing social impact assessments to increase the implementation of such methods in industrial and private company settings.

There are limitations to the completed study. One of the limitations has to do with the generalization of the results across all industry sectors and disciplines. The vast amount of industry sectors considered in the selected articles may limit the generalizability of the results. As an example, $19 \%$ of the articles considered belong to the scope of company management or consulting. Although the goal is to obtain generalizable findings from the systematic mapping procedure, the authors only claim these results to be valid for the selected articles. 
Supplementary Materials: The following are available online at http://www.mdpi.com/2071-1050/11/15/4106/s1, Table S1: Summary of articles selected through systematic map $(n=81)$. Table S2: Summary of case studies $(n=49)$.

Author Contributions: Both authors contributed significantly to the completion of the work presented in the manuscript. R.J.B.-A. contributed to the development of the research plan and completed the Systematic Mapping. K.F. contributed significantly to the structuring of the map and analysis, draft preparation and editing process of the manuscript.

Funding: This research received no external funding.

Conflicts of Interest: The authors declare no conflict of interest.

\section{References}

1. Brundtland, G.H. Report of the World Commission on Environment and Development: Our Common Future; United Nations: Oslo, Norway, 1987.

2. Giddings, B.; Hopwood, B.; O’Brien, G. Environment, economy and society: Fitting them together into sustainable development. Sustain. Dev. 2002, 10, 187-196. [CrossRef]

3. Iofrida, N.; Strano, A.; Gulisano, G.; de Luca, A.I. Why social life cycle assessment is struggling in development? Int. J. Life Cycle Assess. 2018, 23, 201-203. [CrossRef]

4. Benoît, C.; Norris, G.A.; Valdivia, S.; Ciroth, A.; Moberg, A.; Bos, U.; Prakash, S.; Ugaya, C.; Beck, T. The guidelines for social life cycle assessment of products: Just in time! Int. J. Life Cycle Assess. 2010, 15, 156-163. [CrossRef]

5. Rainock, M.; Everett, D.; Pack, A.; Dahlin, E.C.; Mattson, C.A. The social impacts of products: A review. Impact Assess. Proj. Apprais. 2018, 36, 230-241. [CrossRef]

6. Spierling, S.; Knüpffer, E.; Behnsen, H.; Mudersbach, M.; Krieg, H.; Springer, S.; Albrecht, S.; Herrmann, C.; Endres, H.-J.J. Bio-based plastics-A review of environmental, social and economic impact assessments. J. Clean. Prod. 2018, 185, 476-491. [CrossRef]

7. Morgan, R.K.; Esteves, A.M.; Franks, D.; Vanclay, F. Environmental impact assessment: The state of the art. Impact Assess. Proj. Apprais. 2012, 30, 5-14. [CrossRef]

8. Benoît, C.; Norris, G.A.; Valdivia, S.; Ciroth, A.; Moberg, A.; Bos, U.; Prakash, S.; Ugaya, C.; Beck, T. Guidelines for Social Life Cycle Assessment of Products; UNEP/Earthprin: Paris, France, 2009.

9. Lucchetti, M.; Arcese, G.; Traverso, M.; Montauti, C. S-LCA applications: A case studies analysis. E3S Web Conf. 2018, 74, 1-7. [CrossRef]

10. Petti, L.; Serreli, M.; di Cesare, S. Systematic literature review in social life cycle assessment. Int. J. Life Cycle Assess. 2018, 23, 422-431. [CrossRef]

11. Kühnen, M.; Hahn, R. Indicators in Social Life Cycle Assessment: A Review of Frameworks, Theories, and Empirical Experience. J. Ind. Ecol. 2017, 21, 1547-1565. [CrossRef]

12. Di Cesare, S.; Silveri, F.; Sala, S.; Petti, L. Positive impacts in social life cycle assessment: State of the art and the way forward. Int. J. Life Cycle Assess. 2018, 23, 406-421. [CrossRef]

13. James, K.L.; Randall, N.P.; Haddaway, N.R. A methodology for systematic mapping in environmental sciences. Environ. Evid. 2016, 5, 7. [CrossRef]

14. Zumsteg, J.M.; Cooper, J.S.; Noon, M.S. Systematic Review Checklist. J. Ind. Ecol. 2012, 16 (Suppl. 1), S12-S21. [CrossRef] [PubMed]

15. Zamagni, A.; Masoni, P.; Buttol, P.; Raggi, A.; Buonamici, R. Finding Life Cycle Assessment Research Direction with the Aid of Meta-Analysis. J. Ind. Ecol. 2012, 16 (Suppl. 1), S39-S52. [CrossRef]

16. Crossan, M.M.; Apaydin, M. A Multi-Dimensional Framework of Organizational Innovation: A Systematic Review of the Literature. J. Manag. Stud. 2010, 47, 1154-1191. [CrossRef]

17. Ashby, M.F. Materials and the Environment, 2nd ed.; Elsevier: Oxford, UK, 2013.

18. International Organization for Standardization. Environmental Management-Life Cycle Assessment-Requirements and Guidelines; ISO: Geneva, Switzerland, 2006.

19. Jorgensen, A.; le Bocq, A.; Nazarkina, L.; Hauschild, M.; Jørgensen, A.; le Bocq, A.; Nazarkina, L.; Hauschild, M. Methodologies for social life cycle assessment. Int. J. Life Cycle Assess. 2008, 13, 96-103. [CrossRef]

20. International Organization for Standardization. ISO 26000 and OECD Guidelines: Practical Overview of the Linkages; ISO: Vernier, Geneva, 2017. 
21. Freeman, R.E.; Wicks, A.C.; Parmar, B. Stakeholder Theory and "The Corporate Objective Revisited". Organ. Sci. 2004, 15, 364-369. [CrossRef]

22. Biolchini, J.; Gomes-Mian, P.; Cruz-Natali, A.C.; Travassos-Horta, G. Systematic Review in Software Engineering; COPPE/UFRJ: Rio de Janeiro, Brazil, 2005.

23. Mulrow, C.D. Systematic Reviews: Rationale for systematic reviews. BMJ 1994, 309, 597-599. [CrossRef] [PubMed]

24. Clapton, J.; Rutter, D.; Sharif, N. SCIE Sytematic Mapping Guidance; SCIE: London, UK, 2009.

25. United States Department of Commerce. North American Industry Classification System (NAICS). 2017. Available online: https://www.census.gov/eos/www/naics/ (accessed on 10 February 2019).

26. Global Social Venture. Social Impact Assessment. 2008. Available online: https://gsvc.org/wp-content/ uploads/2016/10/Social-Impact-Assessment-Glossary.pdf (accessed on 20 February 2019).

27. Gould, R.; Missimer, M.; Mesquita, P.L. Using social sustainability principles to analyse activities of the extraction lifecycle phase: Learnings from designing support for concept selection. J. Clean. Prod. 2017, 140, 267-276. [CrossRef]

28. Benoit-Norris, C. MEMS and Nanotechnology; Springer: New York, NY, USA, 2011; Volume 2.

29. European Parliament and Council of the European Union. General Data Protection Regulation; European Union: Brussels, Belgium, 2016; pp. 1-88.

30. Sureau, S.; Mazijn, B.; Garrido, S.R.; Achten, W.M.J.J. Social life-cycle assessment frameworks: A review of criteria and indicators proposed to assess social and socioeconomic impacts. Int. J. Life Cycle Assess. 2018, 23, 904-920. [CrossRef]

31. Rafiaani, P.; Kuppens, T.; van Dael, M.; Azadi, H.; Lebailly, P.; van Passel, S. Social sustainability assessments in the biobased economy: Towards a systemic approach. Renew. Sustain. Energy Rev. 2018, 82, 1839-1853. [CrossRef]

32. Russo Garrido, S.; Parent, J.; Beaulieu, L.; Revéret, J.P. A literature review of type I SLCA—Making the logic underlying methodological choices explicit. Int. J. Life Cycle Assess. 2018, 23, 432-444. [CrossRef]

33. Traverso, M.; Bell, L.; Saling, P.; Fontes, J. Towards social life cycle assessment: A quantitative product social impact assessment. Int. J. Life Cycle Assess. 2018, 23, 597-606. [CrossRef]

34. Benoît-Norris, C.; Vickery-Niederman, G.; Valdivia, S.; Franze, J.; Traverso, M.; Ciroth, A.; Mazijn, B. Introducing the UNEP/SETAC methodological sheets for subcategories of social LCA. Int. J. Life Cycle Assess. 2011, 16, 682-690. [CrossRef]

35. Meijer, E.; Gasbeek, A. Handbook on a Novel Methodology for the Sustainability Impact Assessment of New Technologies (PROSUITE); Utrecht University: Utrecht, The Netherlands, 2015.

36. Andrews, E.; Lesage, P.; Benoît, C.; Parent, J.; Norris, G.; Revéret, J.-P. Life Cycle Attribute Assessment. J. Ind. Ecol. 2009, 13, 565-578. [CrossRef]

37. Singh, R. Corporate Social Responsibility for Social Impact: Approach to Measure Social Impact using CSR Impact Index. In Proceedings of the 2013 World IIM conference on Emerging Issues in Management, Goa, India, 30-31 May 2013.

38. Brown, A. Social Life Cycle Metrics for Chemical Products-A Guideline by the Chemical Sector to Assess and Report on the Social Impact of Chemical Products, Based on a Life Cycle Approach; WBCSD: Geneva, Switzerland, 2016.

39. Poverty Reduction Group (PRMPR); Social Development Department (SDV). A User's Guide to Poverty and Social Impact Analysis; The World Bank: Washington, DC, USA, 2003.

40. Nichols Applied Management, Management and Economic Consultants. Benga Mining Limited Grassy Mountain Coal Project Socio-Economic Impact Assessment; Nichols Applied Management Inc.: Edmonton, AB, Canada, 2016.

41. Peruzzini, M.; Gregori, F.; Luzi, A.; Mengarelli, M.; Germani, M. A social life cycle assessment methodology for smart manufacturing: The case of study of a kitchen sink. J. Ind. Inf. Integr. 2017, 7, 24-32. [CrossRef]

42. Grubert, E. Rigor in social life cycle assessment: Improving the scientific grounding of SLCA. Int. J. Life Cycle Assess. 2018, 23, 481-491. [CrossRef]

43. Yıldız-Geyhan, E.; Yılan, G.; Altun-Çiftçioğlu, G.A.; Kadırgan, M.A.N. Environmental and social life cycle sustainability assessment of different packaging waste collection systems. Resour. Conserv. Recycl. 2019, 143, 119-132. [CrossRef] 
44. Holger, S.; Jan, K.; Petra, Z.; Andrea, S.; Jürgen-Friedrich, H. The Social Footprint of Hydrogen Production-A Social Life Cycle Assessment (S-LCA) of Alkaline Water Electrolysis. Energy Procedia 2017, 105, 3038-3044. [CrossRef]

45. Siebert, A.; Bezama, A.; O'Keeffe, S.; Thrän, D. Social life cycle assessment: In pursuit of a framework for assessing wood-based products from bioeconomy regions in Germany. Int. J. Life Cycle Assess. 2018, 23, 651-662. [CrossRef]

46. Norris, C.B.; Aulisio, D.; Norris, G.A. Working with the Social Hotspots Database-Methodology and Findings from 7 Social Scoping Assessments. In Leveraging Technology for a Sustainable World; Springer: Berlin/Heidelberg, Germany, 2012; pp. 581-586.

47. Siebert, A.; O'Keeffe, S.; Bezama, A.; Zeug, W.; Thrän, D. How not to compare apples and oranges: Generate context-specific performance reference points for a social life cycle assessment model. J. Clean. Prod. 2018, 198, 587-600. [CrossRef]

48. Dubois-Iorgulescu, A.-M.; Saraiva, A.K.E.B.; Valle, R.; Rodrigues, L.M. How to define the system in social life cycle assessments? A critical review of the state of the art and identification of needed developments. Int. J. Life Cycle Assess. 2018, 23, 507-518. [CrossRef]

49. Arcese, G.; Lucchetti, M.C.; Massa, I.; Valente, C. State of the art in S-LCA: Integrating literature review and automatic text analysis. Int. J. Life Cycle Assess. 2018, 23, 394-405. [CrossRef]

50. Zanchi, L.; Delogu, M.; Zamagni, A.; Pierini, M. Analysis of the main elements affecting social LCA applications: Challenges for the automotive sector. Int. J. Life Cycle Assess. 2018, 23, 519-535. [CrossRef]

51. Reap, J.; Roman, F.; Duncan, S.; Bras, B. A survey of unresolved problems in life cycle assessment Part 1: Goal and scope and inventory analysis. Int. J. Life Cycle Assess. 2008, 13, 290-300. [CrossRef]

52. Reap, J.; Roman, F.; Duncan, S.; Bras, B. A survey of unresolved problems in life cycle assessment Part 2: impact assessment and interpretation. Int. J. Life Cycle Assess. 2008, 13, 374-388. [CrossRef]

53. Kjaer, L.L.; Pagoropoulos, A.; Schmidt, J.H.; McAloone, T.C. Challenges when evaluating Product/Service-Systems through Life Cycle Assessment. J. Clean. Prod. 2016, 120, 95-104. [CrossRef]

54. Reitinger, C.; Dumke, M.; Barosevcic, M.; Hillerbrand, R. A conceptual framework for impact assessment within SLCA. Int. J. Life Cycle Assess. 2011, 16, 380-388. [CrossRef]

55. Bianchi, A.; Ginelli, E. The social dimension in energy landscapes. City Territ. Archit. 2018, 5, 9. [CrossRef]

56. Janker, J.; Mann, S.; Rist, S. Social sustainability in agriculture-A system-based framework. J. Rural Stud. 2019, 65, 32-42. [CrossRef]

57. Hossain, M.U.; Poon, C.S.; Dong, Y.H.; Lo, I.M.C.; Cheng, J.C.P. Development of social sustainability assessment method and a comparative case study on assessing recycled construction materials. Int. J. Life Cycle Assess. 2018, 23, 1654-1674. [CrossRef]

58. Gregori, F.; Papetti, A.; Pandolfi, M.; Peruzzini, M.; Germani, M. Digital Manufacturing Systems: A Framework to Improve Social Sustainability of a Production Site. Procedia CIRP 2017, 63, 436-442. [CrossRef]

59. Sierra, L.A.; Pellicer, E.; Yepes, V. Method for estimating the social sustainability of infrastructure projects. Environ. Impact Assess. Rev. 2017, 65, 41-53. [CrossRef]

60. Fortier, M.-O.P.; Teron, L.; Reames, T.G.; Munardy, D.T.; Sullivan, B.M. Introduction to evaluating energy justice across the life cycle: A social life cycle assessment approach. Appl. Energy 2019, 236, 211-219. [CrossRef]

61. Van der Velden, N.M.; Vogtländer, J.G. Monetisation of external socio-economic costs of industrial production: A social-LCA-based case of clothing production. J. Clean. Prod. 2017, 153, 320-330. [CrossRef]

62. Wang, S.W.; Hsu, C.W.; Hu, A.H. An analytic framework for social life cycle impact assessment-Part 1: Methodology. Int. J. Life Cycle Assess. 2016, 21, 1514-1528. [CrossRef]

63. Wang, Z.; Osseweijer, P.; Duque, J.P. Assessing social sustainability for biofuel supply chains: The case of aviation biofuel in Brazil. In Proceedings of the 2017 IEEE Conference on Technologies for Sustainability (SusTech), Phoenix, AZ, USA, 12-14 November 2017; Volume 2018, pp. 1-5.

64. Anaya, F.C.; Espírito-Santo, M.M. Protected areas and territorial exclusion of traditional communities: Analyzing the social impacts of environmental compensation strategies in Brazil. Ecol. Soc. 2018, 23 , art8. [CrossRef]

65. Arvidsson, R.; Hildenbrand, J.; Baumann, H.; Islam, K.M.N.; Parsmo, R. A method for human health impact assessment in social LCA: Lessons from three case studies. Int. J. Life Cycle Assess. 2018, 23, 690-699. [CrossRef] 
66. Corona, B.; Bozhilova-Kisheva, K.P.; Olsen, S.I.; Miguel, G.S. Social Life Cycle Assessment of a Concentrated Solar Power Plant in Spain: A Methodological Proposal. J. Ind. Ecol. 2017, 21, 1566-1577. [CrossRef]

67. Dunmade, I.; Udo, M.; Akintayo, T.; Oyedepo, S.; Okokpujie, I.P. Lifecycle Impact Assessment of an Engineering Project Management Process-A SLCA Approach. IOP Conf. Ser. Mater. Sci. Eng. 2018, 413, 012061. [CrossRef]

68. Ekener, E.; Hansson, J.; Gustavsson, M. Addressing positive impacts in social LCA-Discussing current and new approaches exemplified by the case of vehicle fuels. Int. J. Life Cycle Assess. 2018, 23, 556-568. [CrossRef]

69. Fedorova, E.; Pongrácz, E. Cumulative social effect assessment framework to evaluate the accumulation of social sustainability benefits of regional bioenergy value chains. Renew. Energy 2019, 131, 1073-1088. [CrossRef]

70. Fontes, J.; Tarne, P.; Traverso, M.; Bernstein, P. Product social impact assessment. Int. J. Life Cycle Assess. 2018, 23, 547-555. [CrossRef]

71. Gaviglio, A.; Bertocchi, M.; Marescotti, M.E.; Demartini, E.; Pirani, A. The social pillar of sustainability: A quantitative approach at the farm level. Agric. Food Econ. 2016, 4, 15. [CrossRef]

72. Grijalva, P.; Darrow, L.; Mirdad, W. Balance scorecard approach in assessing social impact performance measures. In Proceedings of the International Annual Conference of the American Society for Engineering Management, Charlotte, NC, USA, 26-29 October 2016.

73. Hutchins, M.J.; Richter, J.S.; Henry, M.L.; Sutherland, J.W. Development of indicators for the social dimension of sustainability in a U.S. business context. J. Clean. Prod. 2019, 212, 687-697. [CrossRef]

74. Ibáñez-Forés, V.; Bovea, M.D.; Coutinho-Nóbrega, C.; de Medeiros, H.R. Assessing the social performance of municipal solid waste management systems in developing countries: Proposal of indicators and a case study. Ecol. Indic. 2019, 98, 164-178. [CrossRef]

75. Van Haaster, B.; Ciroth, A.; Fontes, J.; Wood, R.; Ramirez, A. Development of a methodological framework for social life-cycle assessment of novel technologies. Int. J. Life Cycle Assess. 2017, 22, 423-440. [CrossRef]

76. Pelletier, N.; Ustaoglu, E.; Benoit, C.; Norris, G.; Rosenbaum, E.; Vasta, A.; Sala, S. Social sustainability in trade and development policy. Int. J. Life Cycle Assess. 2018, 23, 629-639. [CrossRef]

77. Prasara-A, J.; Gheewala, S.H. Applying Social Life Cycle Assessment in the Thai Sugar Industry: Challenges from the field. J. Clean. Prod. 2018, 172, 335-346. [CrossRef]

78. Sajid, Z.; Lynch, N. Financial Modelling Strategies for Social Life Cycle Assessment: A Project Appraisal of Biodiesel Production and Sustainability in Newfoundland and Labrador, Canada. Sustainability 2018, 10, 3289. [CrossRef]

79. Santos, A.C.; Mendes, P.; Teixeira, M.R. Social life cycle analysis as a tool for sustainable management of illegal waste dumping in municipal services. J. Clean. Prod. 2019, 210, 1141-1149. [CrossRef]

80. Schlör, H.; Venghaus, S.; Zapp, P.; Marx, J.; Schreiber, A.; Hake, J.F. The energy-mineral-society nexus-A social LCA model. Appl. Energy 2018, 228, 999-1008. [CrossRef]

81. Shemfe, M.; Gadkari, S.; Sadhukhan, J. Social Hotspot Analysis and Trade Policy Implications of the Use of Bioelectrochemical Systems for Resource Recovery from Wastewater. Sustainability 2018, 10, 3193. [CrossRef]

82. Siebert, A.; Bezama, A.; O'Keeffe, S.; Thrän, D. Social life cycle assessment indices and indicators to monitor the social implications of wood-based products. J. Clean. Prod. 2018, 172, 4074-4084. [CrossRef]

83. Singh, R.K.; Gupta, U. Social life cycle assessment in Indian steel sector: A case study. Int. J. Life Cycle Assess. 2018, 23, 921-939. [CrossRef]

84. Chen, W.; Holden, N.M. Social life cycle assessment of average Irish dairy farm. Int. J. Life Cycle Assess. 2017, 22, 1459-1472. [CrossRef]

85. Hosseinijou, S.A.; Mansour, S.; Shirazi, M.A. Social life cycle assessment for material selection: A case study of building materials. Int. J. Life Cycle Assess. 2014, 19, 620-645. [CrossRef]

86. Subramanian, K.; Yung, W.K.C. Modeling Social Life Cycle Assessment framework for an electronic screen product-A case study of an integrated desktop computer. J. Clean. Prod. 2018, 197, 417-434. [CrossRef]

87. Falcone, P.; Imbert, E. Social Life Cycle Approach as a Tool for Promoting the Market Uptake of Bio-Based Products from a Consumer Perspective. Sustainability 2018, 10, 1031. [CrossRef]

88. Pelletier, N. Social Sustainability Assessment of Canadian Egg Production Facilities: Methods, Analysis, and Recommendations. Sustainability 2018, 10, 1601. [CrossRef]

89. Hoffenson, S.; Dagman, A.; Söderberg, R. A Multi-objective Tolerance Optimization Approach for Economic, Ecological, and Social Sustainability. Re-Eng. Manuf. Sustain. 2013, 729-734. [CrossRef] 
90. Hede, S.; Nunes, M.J.L.; Ferreira, P.F.V.; Rocha, L.A. Incorporating sustainability in decision-making for medical device development. Technol. Soc. 2013, 35, 276-293. [CrossRef]

91. Peruzzini, M.; Pellicciari, M. Application of Early Sustainability Assessment to Support the Design of Industrial Systems. Ind. Eng. Manag. Syst. 2018, 17, 209-225. [CrossRef]

92. Godskesen, B.; Hauschild, M.; Albrechtsen, H.-J.; Rygaard, M. ASTA-A method for multi-criteria evaluation of water supply technologies to Assess the most SusTainable Alternative for Copenhagen. Sci. Total Environ. 2018, 618, 399-408. [CrossRef] [PubMed]

93. Jiang, Q.; Liu, Z.; Liu, W.; Li, T.; Cong, W.; Zhang, H.; Shi, J. A principal component analysis based three-dimensional sustainability assessment model to evaluate corporate sustainable performance. J. Clean. Prod. 2018, 187, 625-637. [CrossRef]

94. Pesce, M.; Terzi, S.; Al-Jawasreh, R.I.M.; Bommarito, C.; Calgaro, L.; Fogarin, S.; Russo, E.; Marcomini, A.; Linkov, I. Selecting sustainable alternatives for cruise ships in Venice using multi-criteria decision analysis. Sci. Total Environ. 2018, 642, 668-678. [CrossRef] [PubMed]

95. Hussain, M.; Ajmal, M.M.; Gunasekaran, A.; Khan, M. Exploration of social sustainability in healthcare supply chain. J. Clean. Prod. 2018, 203, 977-989. [CrossRef]

96. Shang, Z.; Wang, M.; Su, D.; Liu, Q.; Zhu, S. Ontology based social life cycle assessment for product development. Adv. Mech. Eng. 2018, 10, 168781401881227. [CrossRef]

97. Tecco, N.; Baudino, C.; Girgenti, V.; Peano, C. Innovation strategies in a fruit growers association impacts assessment by using combined LCA and s-LCA methodologies. Sci. Total Environ. 2016, 568, 253-262. [CrossRef]

98. Kono, J.; Ostermeyer, Y.; Wallbaum, H. Trade-Off between the Social and Environmental Performance of Green Concrete: The Case of 6 Countries. Sustainability 2018, 10, 2309. [CrossRef]

99. Vanclay, F. Conceptualising social impacts. Environ. Impact Assess. Rev. 2002, 22, 183-211. [CrossRef]

100. Singh, R.K.; Murty, H.R.; Gupta, S.K.; Dikshit, A.K. An overview of sustainability assessment methodologies. Ecol. Indic. 2012, 15, 281-299. [CrossRef]

101. Umair, S.; Björklund, A.; Petersen, E.E. Social impact assessment of informal recycling of electronic ICT waste in Pakistan using UNEP SETAC guidelines. Resour. Conserv. Recycl. 2015, 95, 46-57. [CrossRef]

102. Ciroth, A.; Eisfeldt, F. PSILCA—A Product Social Impact Life Cycle Assessment Database; GreenDelta GmbH: Berlin, Germany, 2016.

103. World Health Organization. Promotion of Mental Well-Being. 2019. Available online: http://www.searo.who. int/entity/mental_health/promotion-of-mental-well-being/en/ (accessed on 20 April 2019).

104. Keyes, C. Social Well-Being. Am. Sociol. Assoc. 1998, 61, 121-140. [CrossRef]

105. United States Institute of Peace. Guiding Principles for Stabilization and Reconstruction: Social Well-Being. Section 10. 2013. Available online: https://www.usip.org/guiding-principles-stabilization-andreconstruction-the-web-version/social-well-being (accessed on 30 April 2019).

106. Foolmaun, R.K.; Ramjeeawon, T. Comparative life cycle assessment and social life cycle assessment of used polyethylene terephthalate (PET) bottles in Mauritius. Int. J. Life Cycle Assess. 2013, 18, 155-171. [CrossRef]

(C) 2019 by the authors. Licensee MDPI, Basel, Switzerland. This article is an open access article distributed under the terms and conditions of the Creative Commons Attribution (CC BY) license (http://creativecommons.org/licenses/by/4.0/). 